\title{
Effect of alkali metal cations on length and strength of hydrogen bonds in DNA base pairs
}

\author{
O. A. Stasyuk, ${ }^{*[a]}$ M. Solà,${ }^{[a]}$ M. Swart,${ }^{[a, b]}$ C. Fonseca Guerra,${ }^{[c, d]}$, T. M. Krygowski, ${ }^{[\mathrm{e}]}$ H.
} Szatylowicz*f]

[a] Institut de Química Computacional i Catàlisi and Departament de Química, Universitat de Girona, C/ M. Aurèlia Capmany 69, 17003 Girona, Spain

[b] ICREA, Pg. Lluís Companys 23, 08010 Barcelona, Spain

[c] Theoretical Chemistry, Department of Chemistry and Pharmaceutical Sciences, AIMMS, Vrije Universiteit Amsterdam, De Boelelaan 1083, 1081 HV Amsterdam, The Netherlands

[d] Leiden Institute of Chemistry, Leiden University, PO Box 9502, NL-2300 RA Leiden, The Netherlands

${ }^{[e]}$ Department of Chemistry, University of Warsaw, 02-093 Warsaw, Pasteura 1, Poland

${ }^{[f]}$ Faculty of Chemistry, Warsaw University of Technology, Noakowskiego 3, Warsaw 00-664, Poland

\begin{abstract}
For many years non-covalently bonded complexes of nucleobases have attracted considerable interest. However, there is a lack of information about the nature of hydrogen bonding between nucleobases when the bonding is affected by metal coordination to one of the nucleobases, and how the individual hydrogen bonds and aromaticity of nucleobases respond to the presence of the metal cation. Here we report a DFT computational study of nucleobase pairs interacting with alkali metal cations. The metal cations contribute to the stabilization of the base pairs to varying degrees depending on their position. The energy decomposition analysis revealed that the nature of bonding between nucleobases does not change much upon metal coordination. The effect of the cations on individual hydrogen bonds were described by changes in VDD charges on frontier atoms, H-bond length, bond energy from NBO analysis, and delocalization index from QTAIM calculations. The aromaticity changes were determined by HOMA index.
\end{abstract}




\section{TOC}

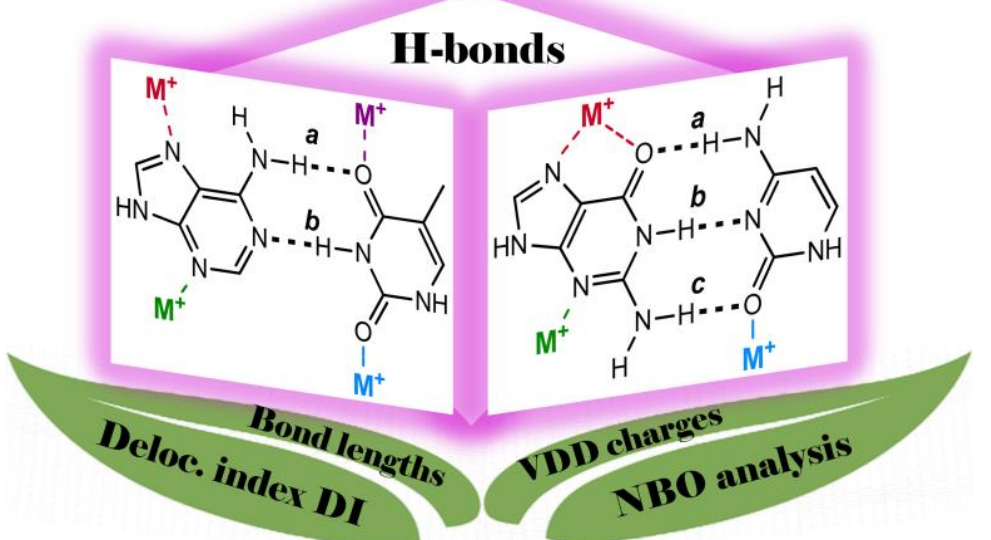

Metal cations affects the hydrogen bonds in DNA base pairs. The strongest bond is $\mathbf{b}$ in AT pair, and $\mathbf{a}$ in GC pair. Interactions with the nitrogen atoms of adenine/guanine promotes the weakening of the strongest bonds, but interactions with the oxygen atoms of thymine/cytosine contribute to their further strengthening.

Keywords: Alkali metals, Aromaticity, Hydrogen bonds, Nucleobases 


\section{Introduction}

It is well known that counterions play an important role in stabilizing the structure of DNA or RNA. Previous experimental and theoretical studies showed that alkali metal cations can bind to different sites of nucleobases and may be located in the minor ${ }^{[1,2,3,4]}$ and major ${ }^{[5,6,7,8]}$ grooves of the double helix (for reviews see Refs. 9,10). Such interactions between metal cations and nucleobases can be direct, or mediated by water molecules of the hydration shell. The large radii of alkali metal cations, unlike divalent cations as $\mathrm{Ca}^{2+}$ and $\mathrm{Mg}^{2+}$, causes them to enter into grooves only with a certain degree of dehydration. ${ }^{[8,11]}$ Such a partial dehydration enables the direct coordination of the alkali metal cations to the different binding sites of nucleobases. ${ }^{[12]}$ Interactions between metal cations and nucleobases or base pairs have been studied because of their biochemical importance. It has been experimentally found that for monovalent and divalent cations the different coordination sites are possible. These different options of coordination are shown in Scheme 1.

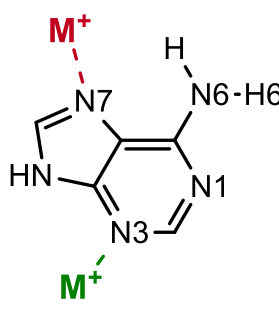

Adenine (A)

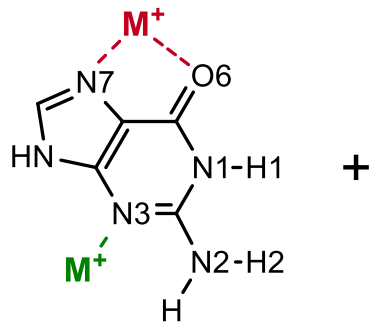

Guanine (G)

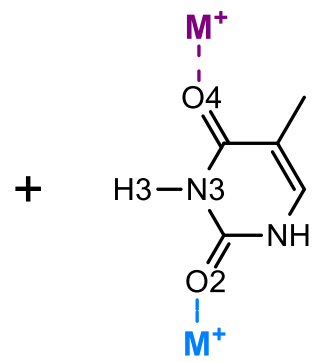

Thymine (T)<smiles></smiles>

Cytosine (C)

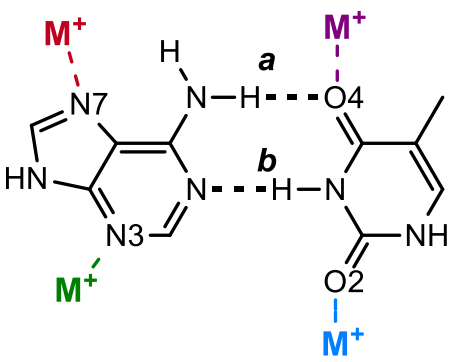

AT

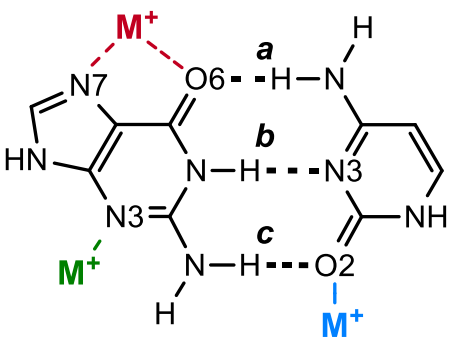

GC

Scheme 1 Possible coordination sites of the alkali metal cations (N3-green, N7-red, O2-blue, O4-purple) to the nucleobases A, T, G, and C, and the Watson-Crick base pairs. The labels $\boldsymbol{a}$, $\boldsymbol{b}$ and $\boldsymbol{c}$ are given for the hydrogen bonds in AT and GC.

For divalent cations, it has been experimentally shown that the coordination at the N7 position of adenine is preferred, ${ }^{[13]}$ whereas for $\mathrm{Ag}^{+}$, the coordination occurs at N3 and N7 of adenine. ${ }^{[14]}$ The bases thymine and uracil bind the metal cations at $\mathrm{O} 4$ atom. ${ }^{[15,16]}$ For guanine and cytosine, the coordination with cation is bifurcated, that is, the metal cation is bound to the $\mathrm{N} 7$ and $\mathrm{O} 6$ atoms of guanine ${ }^{[8,17]}$ and the $\mathrm{N} 3$ and $\mathrm{O} 2$ atoms of cytosine,${ }^{[18,19]}$ respectively. A study by Howerton et al. ${ }^{[6]}$ revealed that structures where the metal cation is located closer to 
an oxygen atom rather than nitrogen atom can be found more often in the Nucleic Acid Database, ${ }^{[20]}$ with the $\mathrm{O} 6$ and N7 of guanine as preferred coordination sites.

Up to now, most theoretical gas-phase studies were devoted to the estimation of the metal-cation affinities for the nucleobases, ${ }^{[21,22,23,24]}$ or to the study of stabilization and destabilization effects on the base pairs caused by metal-cation coordination. ${ }^{[21,22,25]}$ Only a few works were devoted to changes in the individual hydrogen bonds within the Watson-Crick base pairs by the coordination of a metal cation. ${ }^{[26,27,28]}$ Recently, the affinity of quadruplexes for different alkali metal cations have been investigated. ${ }^{[29,30]}$

In this work, we have investigated computationally the coordination of the alkali metal cations $\left(\mathrm{Li}^{+}, \mathrm{Na}^{+}\right.$and $\left.\mathrm{K}^{+}\right)$to the nucleobase pairs in the gas phase and in aqueous solution with dispersion-corrected Density Functional Theory (DFT-D3BJ). The influence of the metal cation on the deformation of the base pairs and the binding of the metal cation to the base pair has been analyzed with Kohn-Sham molecular orbital (MO) theory and corresponding energy decomposition analyses (EDA). ${ }^{[31,32]}$ Furthermore, the effect of the alkali metal cation on the individual hydrogen bond length and strength, as well as on aromaticity of nucleobases has been studied.

\section{Computational Methods}

\subsection{General Procedure}

All calculations were carried out with the Amsterdam Density Functional (ADF) ${ }^{[31,33]}$ and Quantum-regions Interconnected by Local Descriptors (QUILD) ${ }^{34}$ programs using the BLYP functional ${ }^{[35,36]}$ with dispersion corrections D3 as developed by Grimme ${ }^{[37]}$ including the Becke-Johnson (BJ) damping. ${ }^{[38]}$ In a previous study, ${ }^{[39,40]}$ we showed that dispersioncorrected density functionals reproduce well the ab initio results, in particular the BLYP-D functional is in agreement with $a b$ initio results for hydrogen bonding and for $\pi$-stacking interactions in the Watson-Crick base pairs. The basis set is of triple- $\zeta$ quality for all atoms and has been augmented with two sets of polarization functions (TZ2P). ${ }^{[41]}$ The 1 s core shells of $\mathrm{Li}, \mathrm{C}, \mathrm{N}, \mathrm{O}$, and $\mathrm{Na}$ and the $1 \mathrm{~s} 2 \mathrm{~s} 2 \mathrm{p}$ core shells of $\mathrm{K}$ were treated by the frozen-core approximation. Solvent effects in aqueous solution were described using the conductor-like screening model (COSMO) $)^{[42,43]}$ as implemented in ADF program. ${ }^{[44]}$ The solvent effects were treated in an implicit fashion. We have used water as the most polar solvated state that the DNA bases would encounter. The dielectric constant of DNA is much lower and was found to be $\sim 8 .{ }^{[45]}$ We know from previous work that solvation in polar solvents causes a systematic weakening of the hydrogen bonds in AT and GC pairs. ${ }^{[46]}$ To assure that the computed hydration energies of the metal cations correspond to experimental values, we modified radii of the metal cations in the COSMO settings following the proposition from Ref. 47. Such an approach was successfully applied not only for COSMO but also for other continuum solvation 
models. ${ }^{[48,49]}$ To test the validity of using implicit solvation in our systems, we also modelled the most stable complexes of AT and GC with $\mathrm{Na}^{+}$explicitly solvated by one or two water molecules combined with COSMO $(\varepsilon=78.4)$. The similarity of the hydrogen bond lengths and energies obtained by both approaches suggests that implicit solvation is sufficient to reproduce the characteristics of hydrogen bonds (Figure S1 in SI). The vibrational frequencies analysis was performed for all structures. For most complexes, no imaginary frequencies were found for planar structures in $C_{\mathrm{S}}$ symmetry. Only AT_MN7 and GC_MN3 complexes have nonplanar structures as minima. We used the complexes with $C_{\mathrm{s}}$ symmetry throughout the work, as in the DNA structure the nucleobase pairs are forced into planarity by stacking interactions which compensate for the energy spent on planarization. Moreover, the $C_{\mathrm{S}}$ symmetry allows us to decompose the orbital interactions into $\sigma$ - and $\pi$-contributions.

\subsection{Energy and Charge Analyses}

The bond energy, $\Delta E_{\mathrm{Bond}}$, between the bases in the pair is defined for three different situations: (a) the base pair $(\mathrm{AB})$ has no metal cation $\left(\mathrm{M}^{+}\right)$coordinated to the bases $(\mathrm{A}$ and $\mathrm{B})$ :

$$
\Delta E_{\mathrm{Bond}}=E_{\mathrm{AB}}-E_{\mathrm{A}}-E_{\mathrm{B}}
$$

or the base pair has one metal cation $\left(\mathrm{M}^{+}\right)$coordinated to (b) base A or (c) base B:

$$
\begin{aligned}
& \Delta E_{\mathrm{Bond}}=E_{\mathrm{AB}^{-\mathrm{M}^{+}}}-E_{\mathrm{A}-\mathrm{M}^{+}}-E_{\mathrm{B}} \\
& \Delta E_{\mathrm{Bond}}=E_{\mathrm{AB}-\mathrm{M}^{+}}-E_{\mathrm{A}}-E_{\mathrm{B}-\mathrm{M}^{+}}
\end{aligned}
$$

where $E_{\mathrm{AB}}, E_{\mathrm{AB}-\mathrm{M}^{+}}, E_{\mathrm{A}}, E_{\mathrm{B}}, E_{\mathrm{A}-\mathrm{M}^{+}}$and $E_{\mathrm{B}-\mathrm{M}^{+}}$refer to the energy of the base pair and bases (with or without cation) optimized in $C_{\mathrm{S}}$ symmetry.

For the bonding of the metal to the base pair, we define the coordination energy:

$$
\Delta E_{\mathrm{Coord}}=E_{\mathrm{AB}-\mathrm{M}+}-E_{\mathrm{AB}}-E_{\mathrm{M}+}
$$

where $E_{\mathrm{AB}}$ and $E_{\mathrm{AB}-\mathrm{M}}+$ refer to the energy of the base pair without and with cation optimized in $C_{\mathrm{S}}$ symmetry.

As was previously reported, when using the BLYP functional with TZ2P basis set, the basis-set superposition error (BSSE) for H-bond energy is $0.6 \mathrm{kcal} / \mathrm{mol}$ for AT pair and 0.7 $\mathrm{kcal} / \mathrm{mol}$ for GC pair. ${ }^{[50]}$ Since the contribution of BSSE to the bonding energies is almost identical within the set of AT and GC complexes, it was not taking into account in the present work.

The overall bonding energies, $\Delta E_{\mathrm{Bond}}$ and $\Delta E_{\mathrm{Coord}}$, are made up of two major components:

$$
\Delta E_{\mathrm{Bond} / \mathrm{Coord}}=\Delta E_{\mathrm{def}}+\Delta E_{\mathrm{int}}
$$


In this formula, the deformation energy, $\Delta E_{\text {def, }}$ is the amount of energy required to deform the separate fragments from their equilibrium structure to the geometry that they acquire in the total system. The interaction energy, $\Delta E_{\text {int }}$, corresponds to the actual energy change when the prepared fragments are combined to form the total system (for the metal cation alone the deformation energy is zero).

The interaction energy in the gas phase is examined in the framework of the KohnSham MO model using a quantitative energy decomposition analysis (EDA) ${ }^{[51,52,53]}$ into electrostatic interactions, Pauli repulsive orbital interactions, and attractive orbital interactions, to which a term $\Delta E_{\text {disp }}$ is added to account for the dispersion correction:

$$
\Delta E_{\text {int }}=\Delta V_{\text {elstat }}+\Delta E_{\text {Pauli }}+\Delta E_{\mathrm{oi}}+\Delta E_{\text {disp }}
$$

The term $\Delta V_{\text {elstat }}$ corresponds to the classical electrostatic interactions between the unperturbed charge distributions of the prepared (i.e. deformed) bases and is usually attractive. The Pauli repulsion, $\Delta E_{\text {Pauli, }}$, comprises the destabilizing interactions between occupied orbitals and is responsible for any steric repulsion. The orbital interaction, $\Delta E_{\mathrm{oi}}$, accounts for electron-pair bonding, charge transfer (i.e., donor-acceptor interactions between occupied orbitals on one moiety and unoccupied orbitals on the other, including the HOMO-LUMO interactions) and polarization (empty-occupied orbital mixing on one fragment due to the presence of another fragment). The term $\Delta E_{\text {disp }}$ accounts for the dispersion corrections. ${ }^{[41,54,55]}$

The orbital interaction energy can be further decomposed into the contributions from each irreducible representation $\Gamma$ of the interacting system (eq. 5) using the extended transition state (ETS) scheme developed by Ziegler and Rauk. ${ }^{[53]}$ In our planar model systems, this symmetry partitioning allows us to distinguish $\sigma$ and $\pi$ interactions:

$$
\Delta E_{\mathrm{oi}}=\Delta E_{\sigma}+\Delta E_{\pi}
$$

The electron density distribution was analyzed using the Voronoi deformation density (VDD) method. ${ }^{[56,57]}$ The VDD charge $\left(Q_{\mathrm{A}}\right)$ is computed as the numerical integral of the deformation density associated with the formation of the molecule from its atoms in the volume of the Voronoi cell of atom A (eq. 6). The Voronoi cell of an atom A is defined as the compartment of space bounded by the bond midplanes on and perpendicular to all bond axes between nucleus A and its neighboring nuclei. ${ }^{[58]}$

$$
Q_{A}=-\int_{\text {Voronoi cell of } A}\left(\rho(\mathbf{r})-\sum_{B} \rho_{B}(\mathbf{r})\right) d \mathbf{r}
$$

Here, $\rho(\mathrm{r})$ is the electron density of the molecule and the sum over $\rho_{\mathrm{B}}(\mathrm{r})$ is the superposition of 
atomic densities $\rho_{\mathrm{B}}$ of a fictitious promolecule without chemical interactions that is associated with the situation in which all atoms are neutral. Instead of measuring the amount of charge associated with a particular atom $\mathrm{A}, Q_{\mathrm{A}}$ directly monitors how much charge flows, due to chemical interactions, out of $\left(Q_{\mathrm{A}}>0\right)$ or into $\left(Q_{\mathrm{A}}<0\right)$ the Voronoi cell of atom $\mathrm{A}$, that is, the region of space that is closer to nucleus $A$ than to any other nucleus. Thus, VDD method is able to provide a correct treatment of even subtle changes in atomic charges caused by weak chemical interactions (hydrogen bonds) between molecular fragments.

\subsection{Analysis of the individual hydrogen bonds}

The influence of the coordinated metal cation on the individual hydrogen bond strength in the base pairs was analyzed with the natural bond orbital (NBO) analysis ${ }^{[59]}$ and quantum theory of atoms in molecule (QTAIM). ${ }^{[60]}$ According to the NBO analysis, ${ }^{[61]}$ the $\mathrm{N}-\mathrm{H} \cdots \mathrm{Y}$ hydrogen bonding corresponds to an intermolecular donor-acceptor interaction between a lone pair (n) of the Lewis base $(\mathrm{Y})$ and the nearest antibonding orbital $\left(\sigma^{*}\right)$ of the Lewis acid $(\mathrm{N}-\mathrm{H})$ corrected by energy of the steric exchange repulsion between filled $n(Y)$ and $\sigma(N-H)$ orbitals. The strength of such interaction, $E_{\mathrm{NBO}}$, can be estimated as:

$$
E_{N B O}=E_{n \rightarrow \sigma^{*}}^{(2)}+E_{\sigma \rightarrow n}
$$

where $E_{n \rightarrow \pi^{*}}^{(2)}$ means the second-order stabilization energy of the partial donor-acceptor $\mathrm{n}_{\mathrm{Y}} \rightarrow$ $\sigma^{*}{ }_{\mathrm{N}-\mathrm{H}}$ interaction, and $E_{\sigma \rightarrow \mathrm{n}}$ denotes the steric repulsion energy between $\sigma_{\mathrm{N}-\mathrm{H}}$ and $\mathrm{n}_{\mathrm{Y}}$ orbitals (with $\mathrm{Y}=\mathrm{O}$ or $\mathrm{N}$ ).

This energy can characterize only individual hydrogen bonds but not the total interaction energy of the base pair which contains also contributions of other interacting parts of the complex. Therefore, one cannot expect that the sum of individual energies of $\mathrm{N}-\mathrm{H} \cdots \mathrm{Y}$ bonds would be equal to the bonding energy of a given base pair. ${ }^{[62]}$

The QTAIM analysis was performed using the AIMAll program package ${ }^{[63]}$ to provide parameters such as the delocalization index, $D I$. The $D I(\mathrm{~A}, \mathrm{~B})$ corresponds to the number of electrons delocalized or shared between atoms $\mathrm{A}$ and $\mathrm{B}$. For a given $\mathrm{A}-\mathrm{B}$ bond, DI $(\mathrm{A}, \mathrm{B})$ reflects its degree of covalency and can be used for characterization of hydrogen bonds. ${ }^{[26,64,65]}$ $D I$ values are significantly greater than $\rho_{\mathrm{BCP}}$, and therefore more legible for describing subtle effects caused by weak interactions. Calculation of DIs at the DFT level of theory cannot be performed exactly, because the electron-pair density is not available at this level of theory. ${ }^{[66]}$ As an approximation, we used the Kohn-Sham orbitals obtained from the DFT calculation to calculate HF-like DIs using the following expression:

$$
D I(A, B)=4 \sum_{i, j} S_{i j}(A) S_{i j}(B)
$$


where $S_{i j}(\mathrm{~A})$ and $S_{i j}(\mathrm{~B})$ are the overlaps between occupied molecular orbitals $i$ and $j$ on the domains of atoms $\mathrm{A}$ and $\mathrm{B}$, respectively.

The NBO and QTAIM analyzes were performed at the BLYP/6-311++G(2d,2p) level for the molecular geometries of the GC and AT pairs and their metal complexes obtained from the calculations by ADF program.

\subsection{Analysis of aromaticity}

To estimate changes in aromaticity of nucleobases and their individual rings, the geometry-based index of aromaticity HOMA (Harmonic Oscillator Model of Aromaticity) ${ }^{[67,68]}$ was used, which is defined as:

$$
H O M A=1-\frac{1}{n} \sum_{j=1}^{n} \alpha_{i}\left(R_{o p t, i}-R_{j}\right)^{2}
$$

where $n$ is the number of bonds taken into the summation; $\alpha_{i}$ is a normalization constant (for $\mathrm{CC}$ and $\mathrm{CN}$ bonds $\alpha_{\mathrm{CC}}=257.7$ and $\alpha_{\mathrm{CN}}=93.52$ ) fixed to give HOMA $=0$ for a model nonaromatic system and HOMA $=1$ for the system in which all bonds are equal to the optimal value $R_{\mathrm{opt}, i}$ assumed to be realized for fully aromatic systems (for $\mathrm{CC}$ and $\mathrm{CN}$ bonds $R_{\mathrm{opt}, \mathrm{CC}}=1.388 \AA$ and $R_{\mathrm{opt}, \mathrm{CN}}=1.334 \AA$, respectively), and $R_{j}$ denotes the bond lengths that are taken into consideration.

\section{Results and Discussion}

\subsection{Structure and Stability of Base Pairs with Alkali Metal Coordination}

The Watson-Crick base pair AT has four different metal binding sites, whereas GC has only three (see Scheme 1). In the gas phase, the most preferred coordination site at AT, for all three cations, is the $\mathrm{O} 2$ position of thymine followed by $\mathrm{O} 4$, whereas for $\mathrm{GC}$, it is the chelate coordination to N7 and $\mathrm{O} 6$ atoms. In water, there is almost no preference for a particular binding site in the case of AT, whereas for GC, there is a clear preference for the chelate coordination. The relative stabilities for the different coordination sites are given in Table S1. The computed coordination sites are in line with the experimental findings ${ }^{[17,20]}$ and the coordination occurs, according to our previous works on Watson-Crick base pairs, ${ }^{[69,70]}$ to the most negatively charged atom of AT and the most negatively charged part of GC (Figure 1).

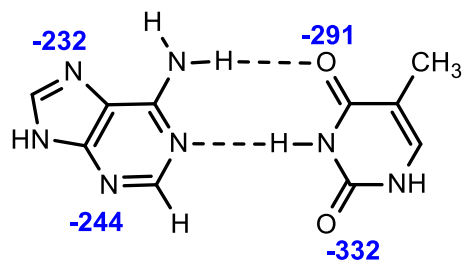

AT

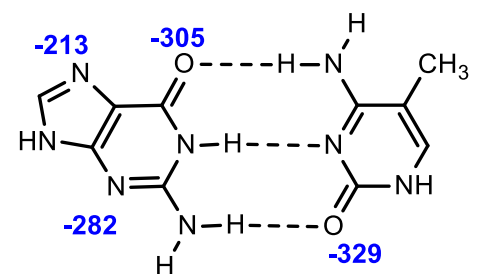

GC 
Figure 1. VDD charges at the basic centers (in milli-electrons) of AT and GC pairs.

The metal coordination affects the interaction energy between the two bases, since one of the bases becomes charged. Figures 2 and 3 represent the hydrogen bond distances and energies for AT and GC with metal cations in the gas phase and in water. In the gas phase, the complexation with metal cations contribute substantially to the stabilization of the base pairs (Table 1). The hydrogen bond energies in natural AT and GC pairs at the BLYP-D3(BJ)/TZ2P level of theory are -16.7 and $-30.5 \mathrm{kcal} / \mathrm{mol}$, respectively. Metal binding to the adenine or guanine leads to an increase in the bonding energies between the two bases (i.e. more favorable), which is consistent with the previously reported results. ${ }^{[22,71]}$ The $\Delta E_{\text {bond }}$ values change quite small when considering non-planar AT_MN7 and GC_MN3 complexes (Table S2). The energetic differences are less than $0.3 \mathrm{kcal} / \mathrm{mol}$ for AT_MN7 and less than 1.1 $\mathrm{kcal} / \mathrm{mol}$ for GC_MN3 complexes. 


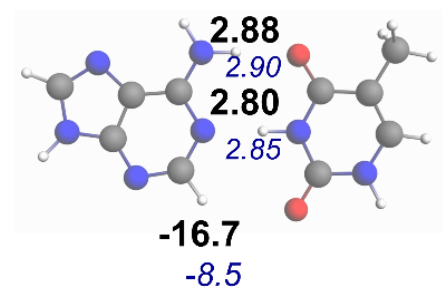

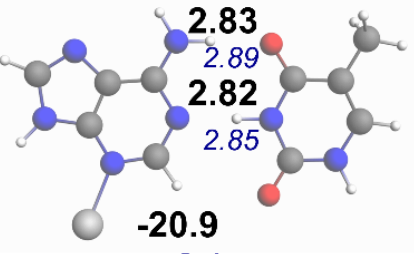

$-8.4$

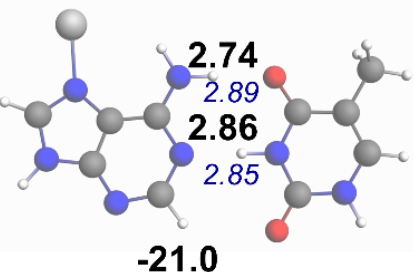

$-8.7$

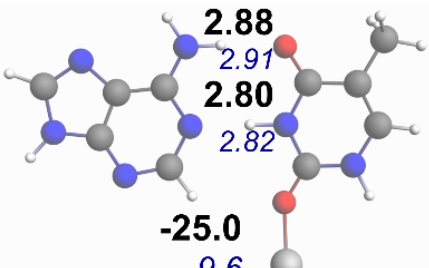

$-9.6$

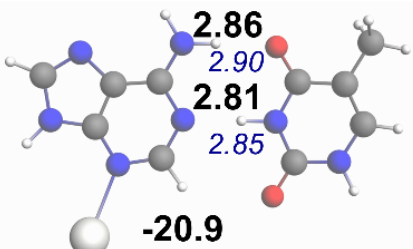

$-8.6$

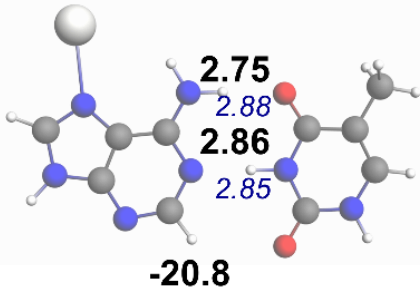

$-9.1$
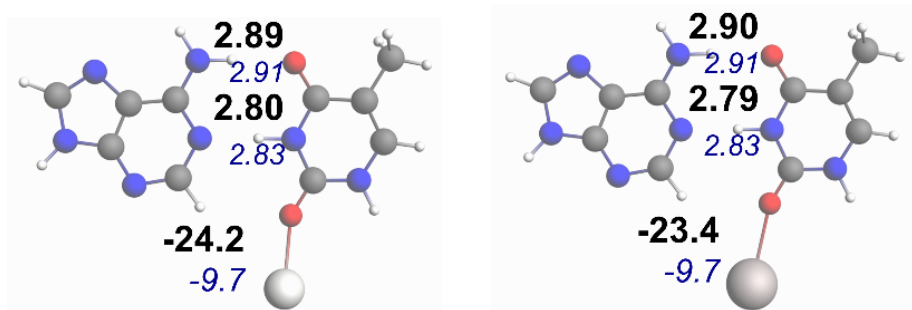

AT MO2

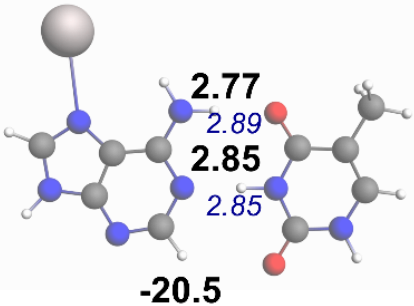

AT MN7

$-8.9$

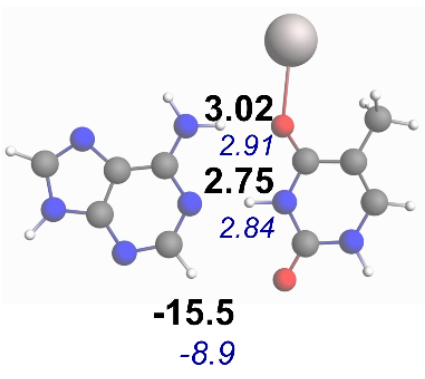

AT MO4

$-16.3$

$-8.7$

$\mathrm{K}^{+}$

Figure 2. Hydrogen bond lengths between proton donor and proton acceptor (in $\AA$ ) and bond energies (in $\mathrm{kcal} / \mathrm{mol}$ ) for the AT base pair without and with the coordinated alkali metals: $\mathrm{Li}^{+}$ (left column), $\mathrm{Na}^{+}$(middle column) and $\mathrm{K}^{+}$(right column), computed at the BLYP$\mathrm{D} 3(\mathrm{BJ}) / \mathrm{TZ2P}$. Gas-phase values are in black and boldfaced, whereas values in water solution are given in blue. 


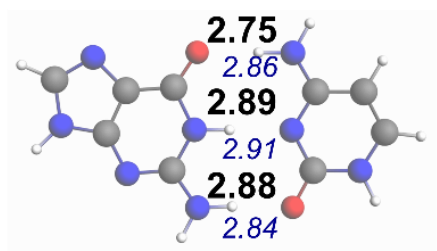

$-30.5$

$-12.3$

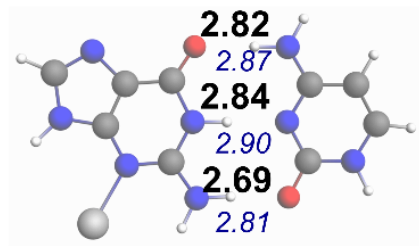

$-44.5$

$-13.4$

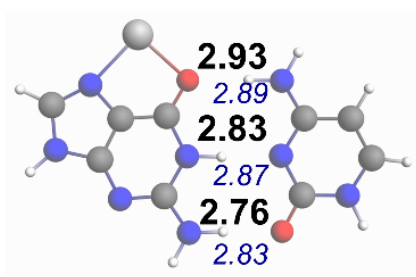

$-37.1$

$-12.9$

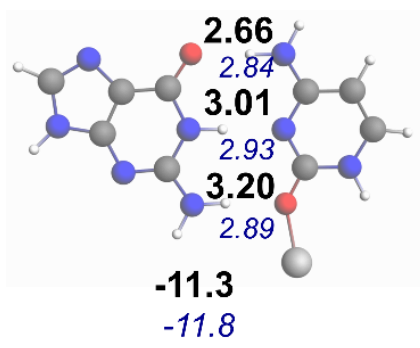

$\mathrm{Li}^{+}$

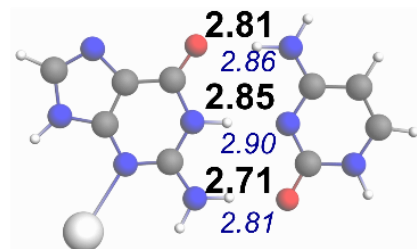

$-43.1$

$-13.0$

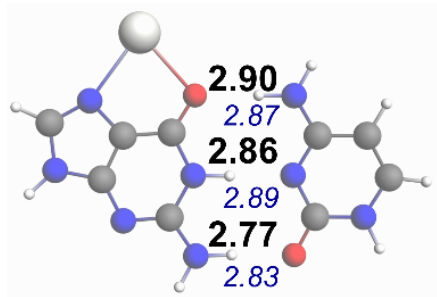

$-35.0$

$-12.9$

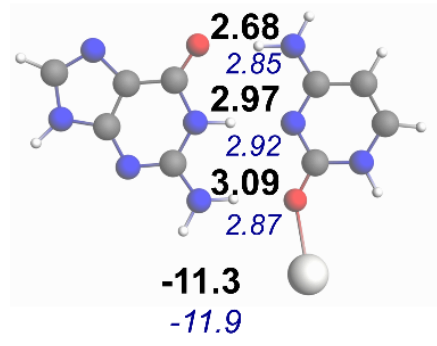

$\mathrm{Na}^{+}$

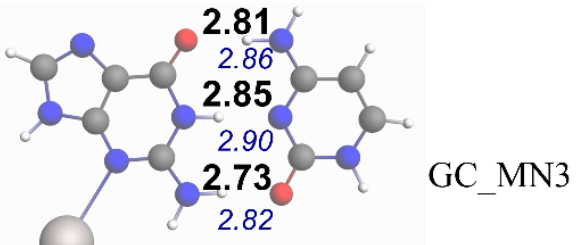

$-41.8$

$-12.7$

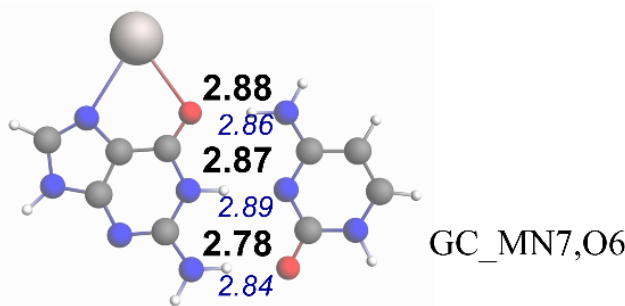

$-33.4$

$-12.7$

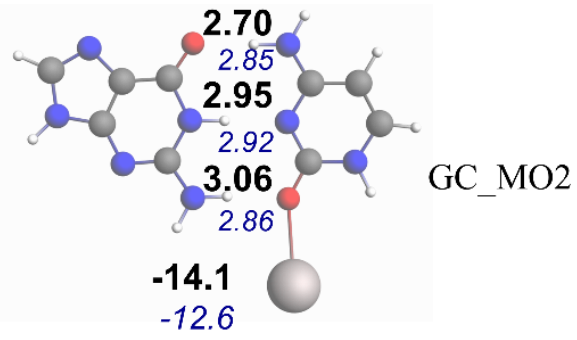

$\mathrm{K}^{+}$

Figure 3. Hydrogen bond lengths between proton donor and proton acceptor (in $\AA$ ) and bond energies (in $\mathrm{kcal} / \mathrm{mol}$ ) for the $\mathrm{GC}$ base pair without and with the alkali metals: $\mathrm{Li}^{+}$(left column), $\mathrm{Na}^{+}$(middle column) and $\mathrm{K}^{+}$(right column) coordinated, computed at the BLYP$\mathrm{D} 3(\mathrm{BJ}) / \mathrm{TZ2P}$. Gas-phase values are in black and boldfaced, whereas values in water solution are given in blue.

For AT pair, the stabilization energy, i.e. $\Delta E_{\text {bond }}\left(\mathrm{AT} \_\mathrm{M}^{+}\right)-\Delta E_{\text {bond }}(\mathrm{AT})$, is up to $4 \mathrm{kcal} / \mathrm{mol}$, whereas for GC pair it is up to $14 \mathrm{kcal} / \mathrm{mol}$, depending on the location of the metal cation. If the cation interacts with the $\mathrm{O} 2$ atom of thymine, a large stabilization (up to $8 \mathrm{kcal} / \mathrm{mol}$ ) is a result of not only H-bond strengthening between two nucleobases, but also extra orbital interactions between the T_MO2 and adenine fragments. The metal cation stabilizes the $\sigma$ LUMO orbitals (Figure 4). In turn, coordination at the $\mathrm{O} 4$ atom of thymine leads to almost no 
changes in the bonding energy of the AT pair, although $\sigma$-LUMOs of the T_MO4 fragment lie significantly lower than $\sigma$-LUMOs of the $\mathrm{T}$ fragment. The reason is a large value of the deformation energy of T_MO4 fragment because the location of the metal cations in the complexes with AT significantly differs from their position in complexes with individual thymine fragment (Figure 5a). For the coordination at $\mathrm{O} 2$ atom of cytosine, the bonding energy of GC pair is conversely weakened due to even larger deformation energy (up to $10 \mathrm{kcal} / \mathrm{mol}$ ). At cytosine the metal cation has a chelate coordination to oxygen and nitrogen, and for the formation of the hydrogen bonds with guanine, the metal cation has to break the bonding with the nitrogen atom of cytosine, which shows up in a large deformation energy of C_MO2 fragment (Figure 5b).

Table 1. EDA of the bonding energy in (metal-coordinated) base pairs (kcal/mol) computed at the BLYP-D3(BJ)/TZ2P level of theory

\begin{tabular}{|c|c|c|c|c|c|c|c|c|c|c|c|c|}
\hline Pair & Base & Pos. & $\mathbf{M}^{+}$ & $\Delta \boldsymbol{E}_{\text {Bon }}$ & $\Delta \boldsymbol{E}_{\text {def }}$ & $\Delta \boldsymbol{E}_{\text {int }}$ & $\Delta \boldsymbol{E}_{\text {Pauli }}$ & $\Delta \boldsymbol{V}_{\text {elstat }}$ & $\Delta E_{\sigma}$ & $\Delta E_{\pi}$ & $\Delta \boldsymbol{E}_{\text {disp }}$ & $\begin{array}{l}\Delta \boldsymbol{E}_{\text {Bond }} \\
(\mathrm{H} 2 \mathrm{O})\end{array}$ \\
\hline \multirow[t]{13}{*}{$\overline{\mathrm{AT}}$} & \multirow{7}{*}{$\frac{\mathscr{\Xi}}{\stackrel{\Xi}{0}}$} & - & - & -16.7 & 1.9 & -18.5 & 40.1 & -32.1 & -19.6 & -1.6 & -5.4 & -8.5 \\
\hline & & \multirow[t]{2}{*}{ N3 } & $\mathrm{Li}^{+}$ & -20.9 & 1.6 & -22.5 & 37.9 & -34.7 & -18.4 & -1.9 & -5.5 & -8.4 \\
\hline & & & $\mathrm{Na}^{+}$ & -20.9 & 1.6 & -22.5 & 38.1 & -35.0 & -18.3 & -1.8 & -5.6 & -8.6 \\
\hline & & \multirow{4}{*}{ N7 } & $\mathrm{K}^{+}$ & -* & - & - & - & - & - & - & - & -8.4 \\
\hline & & & $\mathrm{Li}^{+}$ & -21.0 & 2.2 & -23.2 & 41.0 & -35.3 & -21.0 & -2.5 & -5.4 & -8.7 \\
\hline & & & $\mathrm{Na}^{+}$ & -20.8 & 2.1 & -22.9 & 40.4 & -35.0 & -20.5 & -2.4 & -5.4 & -9.1 \\
\hline & & & $\mathrm{K}^{+}$ & -20.5 & 2.2 & -22.6 & 40.6 & -35.1 & -20.4 & -2.3 & -5.4 & -8.9 \\
\hline & \multirow{6}{*}{$\underset{\Xi}{\stackrel{\Xi}{\Xi}}$} & \multirow[t]{2}{*}{$\mathrm{O} 2$} & $\mathrm{Li}^{+}$ & -25.0 & 3.4 & -28.5 & 40.5 & -31.8 & -25.7 & -4.8 & -6.7 & -9.6 \\
\hline & & & $\mathrm{Na}^{+}$ & -24.2 & 2.6 & -26.8 & 40.5 & -33.0 & -23.3 & -4.2 & -6.8 & -9.7 \\
\hline & & \multirow{4}{*}{ O4 } & $\mathrm{K}^{+}$ & -23.4 & 2.5 & -25.8 & 41.0 & -33.9 & -22.3 & -3.7 & -6.9 & -9.7 \\
\hline & & & $\mathrm{Li}^{+}$ & -17.0 & 8.2 & -25.2 & 51.9 & -36.6 & -30.9 & -3.5 & -6.1 & -8.5 \\
\hline & & & $\mathrm{Na}^{+}$ & -16.3 & 5.0 & -21.3 & 45.3 & -32.6 & -24.9 & -2.8 & -6.3 & -8.7 \\
\hline & & & $\mathrm{K}^{+}$ & -15.5 & 3.8 & -19.3 & 42.6 & -30.3 & -22.4 & -2.5 & -6.6 & -8.9 \\
\hline \multirow[t]{10}{*}{$\overline{\text { GC }}$} & & - & - & -30.5 & 3.5 & -34.0 & 52.0 & -47.8 & -27.5 & -4.5 & -6.3 & -12.3 \\
\hline & \multirow{6}{*}{$\begin{array}{l}\stackrel{\Xi}{\Xi} \\
\underset{\Xi}{\Xi}\end{array}$} & \multirow[t]{3}{*}{ N3 } & $\mathrm{Li}^{+}$ & -44.5 & 5.1 & -49.6 & 60.2 & -60.6 & -35.7 & -6.8 & -6.6 & -13.4 \\
\hline & & & $\mathrm{Na}^{+}$ & -43.1 & 4.9 & -48.0 & 59.0 & -59.5 & -34.5 & -6.5 & -6.6 & -13.0 \\
\hline & & & $\mathrm{K}^{+}$ & -41.8 & 4.8 & -46.6 & 58.3 & -58.5 & -33.6 & -6.3 & -6.6 & -12.7 \\
\hline & & \multirow[t]{3}{*}{ N7,O6 } & $\mathrm{Li}^{+}$ & -37.1 & 3.5 & -40.6 & 51.7 & -51.0 & -29.7 & -5.0 & -6.5 & -12.9 \\
\hline & & & $\mathrm{Na}^{+}$ & -35.0 & 3.2 & -38.2 & 50.2 & -49.1 & -28.2 & -4.6 & -6.6 & -12.9 \\
\hline & & & $\mathrm{K}^{+}$ & -33.4 & 3.2 & -36.5 & 49.7 & -48.0 & -27.3 & -4.4 & -6.6 & -12.7 \\
\hline & \multirow{3}{*}{ 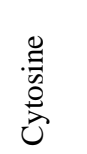 } & \multirow[t]{3}{*}{$\mathrm{O} 2$} & $\mathrm{Li}^{+}$ & -11.3 & 10.1 & -21.4 & 45.4 & -31.4 & -24.5 & -4.0 & -6.8 & -11.8 \\
\hline & & & $\mathrm{Na}^{+}$ & -11.3 & 10.6 & -21.9 & 47.1 & -33.0 & -24.9 & -3.8 & -7.3 & -11.9 \\
\hline & & & $\mathrm{K}^{+}$ & -14.1 & 8.2 & -22.3 & 47.8 & -33.5 & -25.0 & -3.8 & -7.7 & -12.6 \\
\hline
\end{tabular}

* for AT_KN3 complex, $C_{\mathrm{s}}$ symmetric equilibrium structure in the gas phase was not found.

According to the energy decomposition analysis (EDA) of the interaction energy between two nucleobases, ${ }^{[72]}$ the nature of bonding is very similar in the complexes of AT and GC pairs (Table 1). Percentage contributions of electrostatic, orbital interaction, and dispersion terms in the total bonding forces are shown in Figure S2 in SI. The largest contribution is the 
electrostatic interactions (50-60\%) followed by the orbital interactions (35-45\%) and dispersion forces (6-10\%). The nature of bonding does not change much upon metal coordination. When the metal cation interacts with oxygen atoms of thymine or cytosine, the metal participates in the orbital interactions. In this case, $E_{\text {oi }}$ term is slightly larger $(40-45 \%)$ than in the complexes with metal coordination at the nitrogen atoms of adenine or guanine (35$38 \%$ ) due to larger stabilization effect on the accepting $\sigma$-LUMOs of thymine/cytosine and reduction of the orbital-energy gap with lone-pair donor orbitals of the adenine/guanine. The net effect of the metal cation on the different energy components is not so large, because the metal coordination stabilizes some and destabilizes other H-bonds in the complexes of both AT and GC pairs. The effect of metal cations on the individual $\mathrm{H}$-bonds will be considered in detail in section 3.4 .

The stabilization effect of cations becomes very small when a highly polar solvent is taken into account (last column in Table 1). A systematic weakening of the hydrogen bonds in AT and GC pairs upon solvation in polar solvents was previously reported. ${ }^{[46]}$ Calculations in aqueous solution (COSMO) show that changes in hydrogen bond energy caused by metal cation are only a few tenths of $\mathrm{kcal} / \mathrm{mol}$, with a maximum value of $1.2 \mathrm{kcal} / \mathrm{mol}$. This result is in agreement with previous studies where solvent effect was treated by an explicit model. ${ }^{[21,28,73]}$

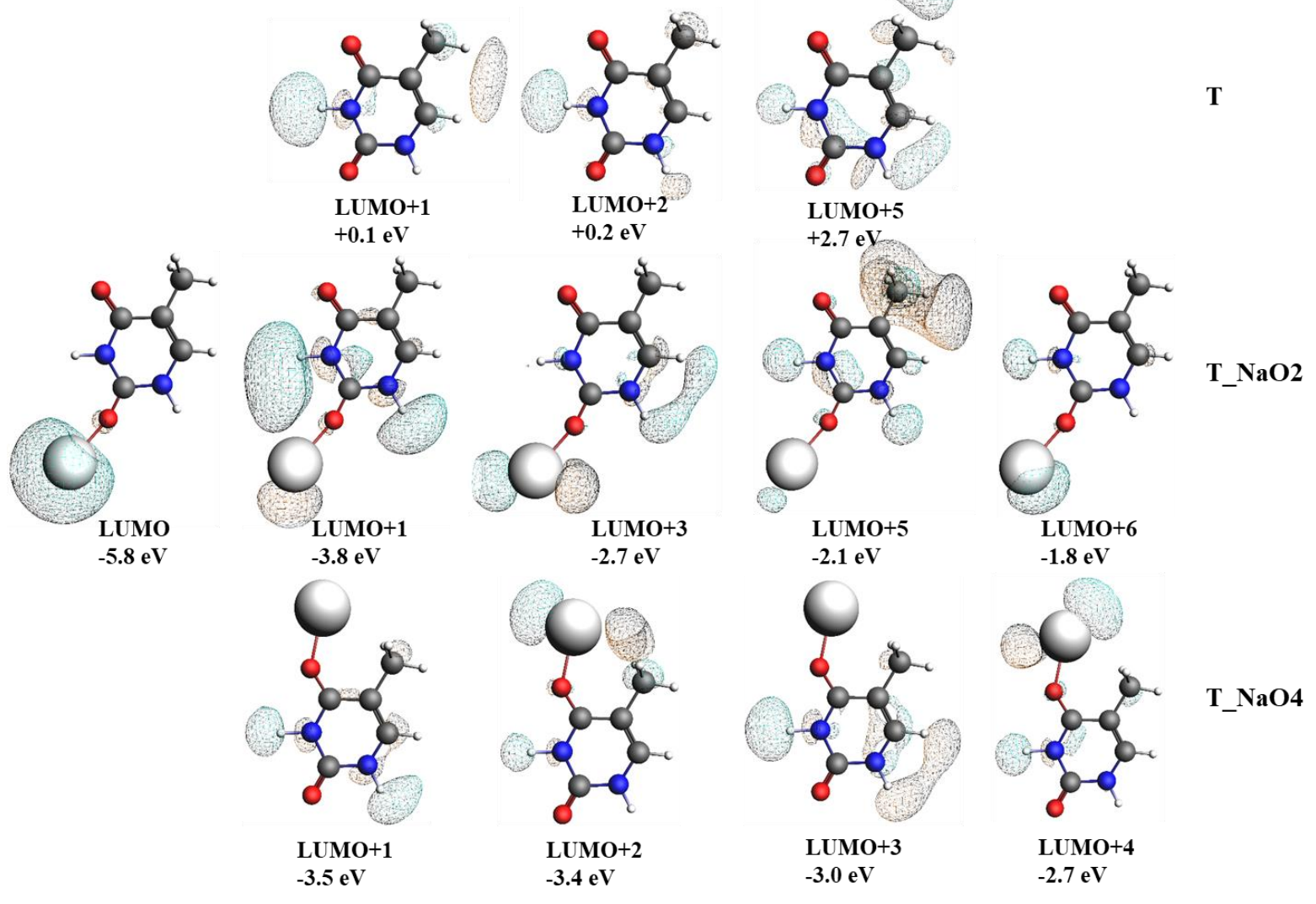


Figure 4. $\sigma$-LUMOs participated in donor-acceptor interactions with adenine and their energies for the thymine fragment in AT pair and its AT_NaO2 and AT_NaO4 complexes computed at the BLYP-D3(BJ)/TZ2P level of theory.

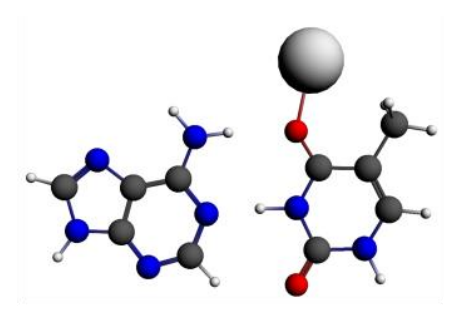

(a)

AT-M

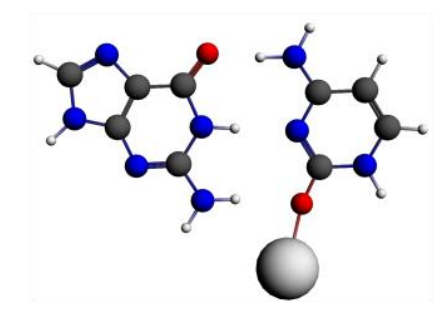

(b)

$\mathrm{GC}^{-\mathrm{M}^{+}}$

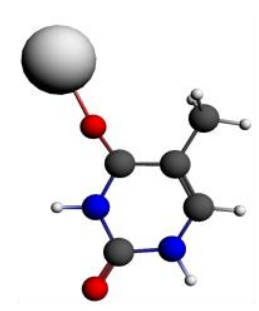

$\mathrm{T}-\mathrm{M}^{+}$

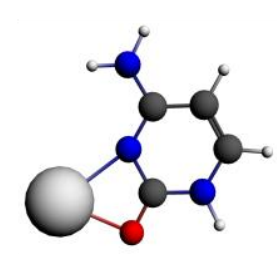

$\mathrm{C}-\mathrm{M}^{+}$

Figure 5. Equilibrium structures of complexes for AT and individual thymine (a), and GC and individual cytosine (b) with metal cation.

\subsection{Metal binding and Energy Decomposition Analysis}

Table 2 shows coordination energies for the studied binding sites. As can be seen, the interaction energy between cation and base pair depends both on the location of cation and on its type. The interaction strength always decreases with increasing ionic radii, i.e. from $\mathrm{Li}^{+}$to $\mathrm{K}^{+}$; interactions with the oxygen atoms are regularly stronger than with the nitrogen ones. Similar results were also found for the individual nucleobases interacting with alkali metal cations. ${ }^{[74,75,76,77]}$ The strongest binding energies for AT pair are observed for $\mathrm{O} 2 \ldots \mathrm{M}^{+}$cases, whereas in GC pair the largest energies belong to chelate complexes with $\mathrm{N} 7, \mathrm{O} 6 \ldots \mathrm{M}^{+}$ interactions. In aqueous solution, the distance between the base pairs and the cations increases and energy values decrease by 5-8 times for complexes of both base pairs (last column in Table 2).

To define the nature of metal binding and describe the observed trends in energetics we performed the energy decomposition analysis of interactions between metal cations and base pairs (Table 2). As can be seen, all energetic terms excluding Pauli repulsion change monotonically from complexes with $\mathrm{Li}^{+}$to complexes with $\mathrm{K}^{+}$, i.e. in line with the increasing distance between cation and interacting atom of the nucleobases. The only exception is the Pauli repulsion, which is smaller for the interaction with $\mathrm{Na}^{+}$than with $\mathrm{Li}^{+}$and $\mathrm{K}^{+}$. This was already observed in study of stabilization effects in guanine quadruplexes. ${ }^{[29]}$ The explanation 
is connected with a balance in interatomic distance and ionic radius of the cation. The repulsion term for interaction with $\mathrm{Li}^{+}$is large because of too close contact between the lone pairs of oxygen or nitrogen atoms and own electrons of the $\mathrm{Li}^{+}$, whereas for interaction with larger and more diffuse cation $\mathrm{K}^{+}$, the large contact area is responsible for more repulsive energy.

According to the EDA, the metal-base pair interaction is not only electrostatic but there is also contribution of orbital interactions. The percentages of electrostatic, orbital interaction and dispersion terms in the total bonding forces is presented in Figure S3 in SI. The more electrostatic are the interactions in chelate complexes of $\mathrm{Na}^{+}$and $\mathrm{K}^{+}$with $\mathrm{GC}\left(\mathrm{GC} \_\mathrm{N} 7, \mathrm{O} 6 \cdots \mathrm{Na}^{+}\right.$ and $\left.\mathrm{GC} \_\mathrm{N} 7, \mathrm{O} 6 \cdots \mathrm{K}^{+}\right), \Delta V_{\text {elstat }}>70 \%$. In turn, the largest contribution of orbital interaction term $\left(\Delta E_{\mathrm{oi}}>40 \%\right)$ is observed for interactions between oxygen atom and $\mathrm{Li}^{+}$in complexes of both base pairs. This can be ascribed to greater overlap between the lowest unoccupied molecular orbital of $\mathrm{Li}^{+}$and highest occupied molecular orbital of the base pair because of closer distances between interacting atoms, and more similar size. The dispersion contribution is small for all complexes and contributes no more than $10 \%$ for complexes with $\mathrm{K}^{+}$, and no more than $5 \%$ for complexes with $\mathrm{Li}^{+}$.

Table 2. EDA of the coordination energy between the base pairs and the metal cations (kcal/mol) computed at the BLYP-D3(BJ)/TZ2P level of theory

\begin{tabular}{|c|c|c|c|c|c|c|c|c|c|c|c|}
\hline Pair & Base & Pos. & $\mathbf{M}^{+}$ & $\Delta \boldsymbol{E}_{\text {Bond }}$ & $\Delta \boldsymbol{E}_{\mathrm{def}}$ & $\Delta \boldsymbol{E}_{\text {int }}$ & $\Delta \boldsymbol{E}_{\text {Pauli }}$ & $\Delta \boldsymbol{V}_{\text {elstat }}$ & $\Delta \boldsymbol{E}_{\mathrm{oi}}$ & $\Delta \boldsymbol{E}_{\text {disp }}$ & $\underbrace{\Delta \boldsymbol{E}_{\text {Bond }}}_{(\mathrm{H} 2 \mathrm{O})}$ \\
\hline \multirow[t]{12}{*}{ AT } & \multirow{9}{*}{ 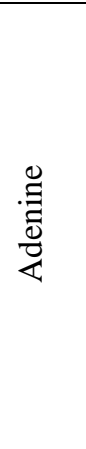 } & \multirow[t]{3}{*}{ N3 } & $\mathrm{Li}^{+}$ & $\begin{array}{l}-52.8 \\
\end{array}$ & 2.0 & -54.9 & 19.0 & -44.2 & -27.6 & -2.1 & \begin{tabular}{|l|}
-7.3 \\
\end{tabular} \\
\hline & & & $\mathrm{Na}^{+}$ & -38.0 & 1.5 & -39.4 & 13.4 & -34.2 & -16.3 & -2.4 & -7.1 \\
\hline & & & $\mathrm{K}^{+}$ & - & - & - & - & - & - & - & -5.3 \\
\hline & & \multirow[t]{3}{*}{ N7 } & $\mathrm{Li}^{+}$ & -48.2 & 2.5 & -50.7 & 19.9 & -41.2 & -26.8 & -2.6 & -6.7 \\
\hline & & & $\mathrm{Na}^{+}$ & -33.3 & 1.8 & -35.1 & 14.4 & -30.8 & -15.7 & -3.0 & -6.2 \\
\hline & & & $\mathrm{K}^{+}$ & -22.7 & 1.4 & -24.0 & 15.0 & -23.3 & -12.7 & -3.0 & -5.2 \\
\hline & & \multirow[t]{3}{*}{$\mathrm{O} 2$} & $\mathrm{Li}^{+}$ & -60.1 & 3.0 & -63.1 & 18.5 & -42.4 & -36.1 & -3.1 & -8.4 \\
\hline & & & $\mathrm{Na}^{+}$ & -43.0 & 2.0 & -45.0 & 12.6 & -34.2 & -20.1 & -3.3 & -7.9 \\
\hline & & & $\mathrm{K}^{+}$ & -33.1 & 1.7 & -34.8 & 14.4 & -29.3 & -16.5 & -3.4 & -6.5 \\
\hline & \multirow{3}{*}{$\underset{\Xi}{\stackrel{\Xi}{\Xi}}$} & \multirow[t]{3}{*}{$\mathrm{O} 4$} & $\mathrm{Li}^{+}$ & -55.0 & 4.8 & -59.8 & 20.5 & -42.5 & -34.7 & -3.1 & -7.0 \\
\hline & & & $\mathrm{Na}^{+}$ & -37.6 & 2.8 & -40.4 & 14.3 & -31.5 & -19.5 & -3.8 & -7.5 \\
\hline & & & $\mathrm{K}^{+}$ & -27.4 & 2.0 & -29.4 & 15.9 & -24.6 & -16.6 & -4.2 & -6.7 \\
\hline \multirow[t]{9}{*}{ GC } & \multirow{6}{*}{$\begin{array}{l}\text { 节 } \\
\text { J }\end{array}$} & \multirow[t]{3}{*}{ N3 } & $\mathrm{Li}^{+}$ & -49.5 & 3.8 & -53.3 & 21.5 & -43.2 & -28.8 & -2.8 & -6.2 \\
\hline & & & $\mathrm{Na}^{+}$ & -33.7 & 2.8 & -36.6 & 15.6 & -31.7 & -17.2 & -3.3 & -6.2 \\
\hline & & & $\mathrm{K}^{+}$ & -22.3 & 2.2 & -24.6 & 15.8 & -23.3 & -13.7 & -3.4 & -4.3 \\
\hline & & \multirow[t]{3}{*}{$\mathrm{N} 7, \mathrm{O} 6$} & $\mathrm{Li}^{+}$ & -83.5 & 5.8 & -89.3 & 20.7 & -69.8 & -38.1 & -2.1 & -9.9 \\
\hline & & & $\mathrm{Na}^{+}$ & -63.7 & 3.2 & -66.9 & 17.9 & -60.2 & -21.9 & -2.6 & -11.8 \\
\hline & & & $\mathrm{K}^{+}$ & -48.9 & 2.2 & -51.1 & 21.9 & -51.7 & -18.5 & -2.8 & -9.1 \\
\hline & \multirow{3}{*}{ 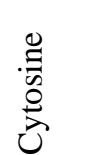 } & \multirow[t]{3}{*}{$\mathrm{O} 2$} & $\mathrm{Li}^{+}$ & -52.6 & 5.2 & -57.8 & 19.2 & -41.2 & -33.2 & -2.6 & -7.7 \\
\hline & & & $\mathrm{Na}^{+}$ & -34.8 & 3.2 & -38.0 & 12.9 & -29.6 & -18.3 & -3.1 & -7.1 \\
\hline & & & $\mathrm{K}^{+}$ & -25.2 & 2.6 & -27.8 & 15.2 & -23.2 & -16.3 & -3.5 & -6.0 \\
\hline
\end{tabular}




\subsection{Choice of approach for estimation of individual H-bonds}

To select the most suitable approach for the description of individual hydrogen bonds in Watson-Crick base pairs several different methods were tested on the AT base pair and its complexes with lithium cation. For this purpose we applied a rotation scheme, ${ }^{[78]}$ where one of the bases was rotated with respect to the other one by 90 or 180 degrees around the axis of each H-bond. As it turned out, this method does not work well for cases with metal cations, where rotation around $\mathrm{H}$-bond axis did not exclude other intermolecular interactions, in particular binding with metal cation. The second approach was the extended transition state (ETS) method for EDA combined with the natural orbitals for chemical valence (NOCV) theory. ${ }^{[79]}$ From this method we hoped to obtain orbital energy contributions from particular H-bonds to the total bond energy between two fragments. However, this proved impossible since particular NOCV orbitals contained contributions from several H-bonds simultaneously (Table S3). The third approach was based on the same EDA scheme only with removing of all virtual orbitals from one fragment and then from another one to switch off appropriate H-bonds and calculate energy of remaining H-bonds. For GC, it is impossible to switch off each H-bond separately, where three conventional $\mathrm{H}$-bonds are. Removing virtuals from the guanine fragment we cancel b and c H-bonds together and can evaluate energy of bond a (Scheme 1). However, if we remove virtuals from the cytosine fragment, we can obtain only a sum of both $\mathbf{b}$ and $\mathbf{c}$ bonds. Another possibility is using the bond energy from natural bond orbital (NBO) analysis ${ }^{[61]}$ and delocalization index from quantum theory of atoms in molecule (QTAIM) ${ }^{[60]}$ for description of changes in individual $\mathrm{H}$-bonds. We are aware that these descriptors do not provide an exact assessment of individual H-bond strength but they can be effectively applied for comparison at a qualitative level. The comparison of all approaches is given in Table S4. A good correlation between NBO energy and some QTAIM parameters was previously reported for $\mathrm{DNA}^{[80]}$ and $\mathrm{RNA}^{[81]}$ base pairs.

\subsection{Effect of the alkali metal cation on the individual hydrogen bonds}

The metal cation can affect the individual $\mathrm{H}$-bonds in the base pairs to varying degree depending on its location. According to previous studies in the gas phase, ${ }^{[62,82,83,84]}$ in base pair AT the strongest bond is the second bond $\mathbf{b}$ and in GC it is the first bond $\mathbf{a}$ (Scheme 1, Table S5). It has been found that coordination of the metal cation to the nitrogen atoms of adenine or guanine promotes the weakening of the strongest bonds, while coordination at the oxygen atoms of thymine or cytosine contributes to their further strengthening. Similar trends were observed in both pairs: interaction with the $\mathrm{O}$ atoms always results in inverse consequences than with the $\mathrm{N}$ atoms. Such observations were confirmed by three descriptors: (i) H-bond length (Figures 2 and 3), (ii) bond energy from NBO analysis and (iii) delocalization index from QTAIM calculations (Tables 3 and 4). For comparison, the electron density $\rho_{B C P}$ values are presented in Tables S6 and S7 in SI. 
Firstly, the changes in individual H-bonds induced by metal cation can be understood if we attentively consider changes in electrostatic attraction between nucleobases, as it was proposed in the study of substituent effects in Watson-Crick base pairs. ${ }^{[85,86]}$ However, the nature of $\mathrm{H}$-bond is not only electrostatic. Thus, changes in charge-transfer part should also be considered. For the investigation of electrostatics, VDD atomic charges were calculated. As expected, the most important changes occur at the atoms directly involved in the hydrogen bonding (Tables S8 and S9). Their study allows us to describe all observed trends in H-bond changes. In adenine, interaction of cation with nitrogen atoms of adenine (N3 or N7) promotes a withdrawal of electronic density from the H-bonding area making the $\mathrm{H} 6$ atom of amino group more positive and the $\mathrm{N} 1$ atom less negative. In the case of $\mathrm{Na}^{+}$, atomic charge on the H6 atom increases from 159 to 193 and 188 milli-electrons for the N3 and N7 coordination place, respectively (Figure 6). Thus, increased electrostatic attraction causes contraction of the length of the hydrogen bond $\mathbf{a}$. For description of changes in covalent contribution of individual $\mathrm{H}$-bonds, the interaction energy from NBO analysis and delocalization index (DI) from QTAIM were used. According to NBO analysis, the attractive donor-acceptor interaction between the lone pair of $\mathrm{O} 4$ atom and unoccupied orbital of the N6-H6 becomes larger despite the increased steric repulsion between the filled orbitals due to shorter distance between them. The delocalization index $D I$ also increases, which points to strengthening of covalent part of this bond. ${ }^{[64]}$ Conversely, the hydrogen bond $\mathbf{b}$ becomes longer due to smaller electrostatic attraction with less negative N1 atom (-210 and -209 milli-electrons in AT_NaN3 and AT_NaN7 vs. -246 milli-electrons in AT). This leads also to a decrease in donor-acceptor interaction as evidenced by $E_{\mathrm{NBO}}$ and $D I$ for this H-bond compared to AT pair. In turn, interaction of metal cation with the $\mathrm{O} 2$ or $\mathrm{O} 4$ atom of thymine promotes an elongation and weakening of the $\mathrm{H}$-bond a due to decreased negative charge on the $\mathrm{O} 4$ atom, but makes the $\mathrm{H}$-bond b shorter and stronger because the $\mathrm{H} 3$ atom becomes more positive. Concurrently, $E_{\mathrm{NBO}}$ and $D I$ parameters indicate a decrease in orbital interactions in the H-bond a but an increase in the H-bond $\mathbf{b}$.

Table 3. Characteristics of the individual H-bonds for AT pair (bold numbers) and its metal complexes calculated in the gas phase and aqueous solution (COSMO). $E_{\mathrm{NBO}}$ in $\mathrm{kcal} / \mathrm{mol}$.

\begin{tabular}{|c|c|c|c|c|c|c|c|c|c|c|c|c|}
\hline & \multicolumn{6}{|c|}{ Gas phase } & \multicolumn{6}{|c|}{ Aqueous solution } \\
\hline & $\begin{array}{l}D I \\
\mathbf{L i}^{+}\end{array}$ & $\begin{array}{l}D I \\
\mathbf{N a}^{+}\end{array}$ & $\begin{array}{l}D I \\
\mathbf{K}^{+}\end{array}$ & $\begin{array}{l}E_{\mathrm{NBO}} \\
\mathbf{L i}^{+}\end{array}$ & $\begin{array}{l}E_{\mathrm{NBO}} \\
\mathbf{N a}^{+}\end{array}$ & $\begin{array}{l}E_{\mathrm{NBO}} \\
\mathbf{K}^{+}\end{array}$ & $\begin{array}{l}D I \\
\mathbf{L i}^{+}\end{array}$ & $\begin{array}{l}D I \\
\mathbf{N a}^{+}\end{array}$ & $\begin{array}{l}D I \\
\mathbf{K}^{+}\end{array}$ & $\begin{array}{l}E_{\mathrm{NBO}} \\
\mathbf{L i}^{+}\end{array}$ & $\begin{array}{l}E_{\mathrm{NBO}} \\
\mathbf{N a}^{+}\end{array}$ & $\begin{array}{l}E_{\mathrm{NBO}} \\
\mathbf{K}^{+}\end{array}$ \\
\hline \multicolumn{13}{|c|}{ AT } \\
\hline $\mathbf{a}$ & & 0.104 & & & -3.2 & & & 0.103 & & & -3.1 & \\
\hline b & & 0.161 & & & -6.6 & & & 0.148 & & & -5.4 & \\
\hline \multicolumn{13}{|c|}{ AT_MN3 } \\
\hline $\mathbf{a}$ & 0.121 & 0.113 & $-{ }^{*}$ & -6.0 & -5.0 & $-*$ & 0.105 & 0.104 & 0.103 & -3.3 & -3.2 & -3.1 \\
\hline b & 0.138 & 0.143 & $-{ }^{*}$ & -3.3 & -3.7 & $-*$ & 0.144 & 0.145 & 0.147 & -5.2 & -5.3 & -5.4 \\
\hline \multicolumn{13}{|c|}{ AT_MN7 } \\
\hline $\mathbf{a}$ & 0.144 & 0.139 & 0.135 & -7.2 & -6.4 & -5.8 & 0.106 & 0.106 & 0.105 & -3.3 & -3.4 & -3.3 \\
\hline
\end{tabular}




\begin{tabular}{lllllll|llllll} 
b & 0.133 & 0.135 & 0.139 & -3.5 & -3.7 & -4.0 & 0.145 & 0.146 & 0.147 & -5.1 & -5.2 & -5.3 \\
AT_MO2 & & & & & & & & & & & & \\
a & 0.097 & 0.097 & 0.095 & -2.5 & -2.5 & -2.4 & 0.101 & 0.101 & 0.101 & -2.9 & -2.9 & -2.9 \\
b & 0.169 & 0.166 & 0.167 & -8.3 & -7.6 & -7.7 & 0.156 & 0.154 & 0.153 & -6.5 & -6.2 & -6.0 \\
AT_MO4 & & & & & & & & & & & & \\
a & 0.073 & 0.079 & 0.085 & -0.7 & -0.7 & -1.0 & 0.092 & 0.097 & 0.101 & -1.2 & -2.1 & -2.4 \\
b & 0.229 & 0.201 & 0.187 & -20.5 & -13.6 & -10.8 & 0.157 & 0.153 & 0.150 & -6.7 & -6.2 & -5.8
\end{tabular}

* No equilibrium structure.

In $\mathrm{GC}$ base pair, interaction of cation with guanine $\mathrm{N} 3$ or N7, O6 active centers induces electron density inflow to the binding place making both hydrogen atoms participating in $\mathbf{b}$ and c H-bonds more positive, while O6 atom becomes less negative (Figure 7). Changes in electrostatic attraction between front atoms cause a contraction of the bonds $\mathbf{b}$ and $\mathbf{c}$ and elongation of the bond a (Figure 3). For the interaction of cation with the $\mathrm{O} 2$ atom of cytosine, H-bond a becomes shorter (the H4 atomic charge increases from 169 to 197 milli-electrons), but the bonds $\mathbf{b}$ and $\mathbf{c}$ become conversely longer due to reduced negative atomic charges on the $\mathrm{N} 3$ and $\mathrm{O} 2$ atoms. Similar to the AT pair, covalent contribution in individual H-bonds of GC pair changes upon metal coordination. An increase in charge-transfer interactions, characterized by changes in $E_{\mathrm{NBO}}$, is observed for the bonds $\mathbf{b}$ and $\mathbf{c}$ when guanine coordinates with metal cation (GC_MN3 and GC_MN7,O6), and for the bond a when the coordination site is the $\mathrm{O} 2$ atom of cytosine; the delocalization index shows the same tendency (Table 4).

Table 4. Characteristics of individual H-bonds for GC pair (bold numbers) and its metal complexes calculated in the gas phase and aqueous solution (COSMO). $E_{\mathrm{NBO}}$ in $\mathrm{kcal} / \mathrm{mol}$.

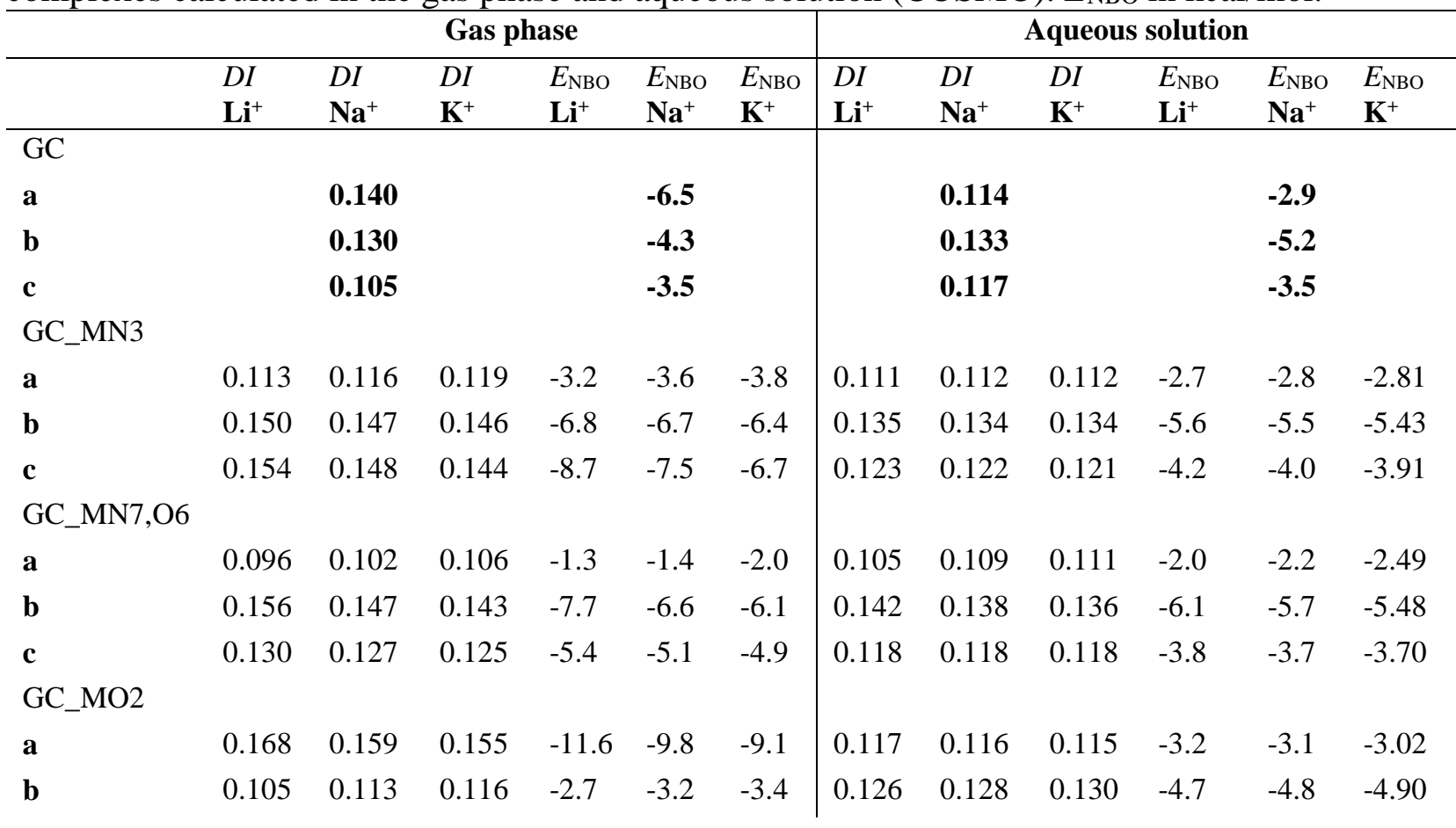




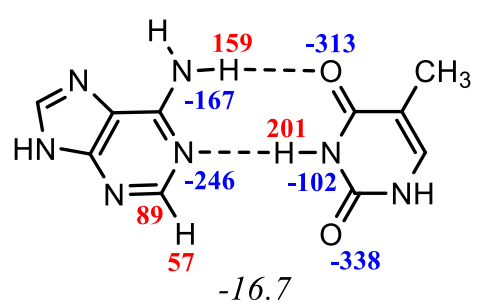

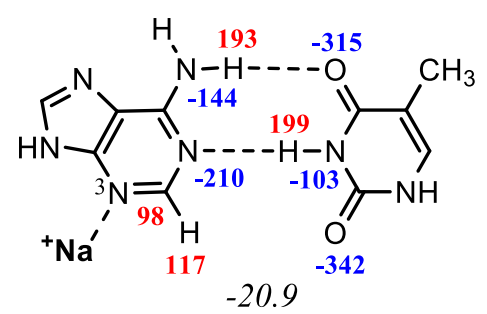

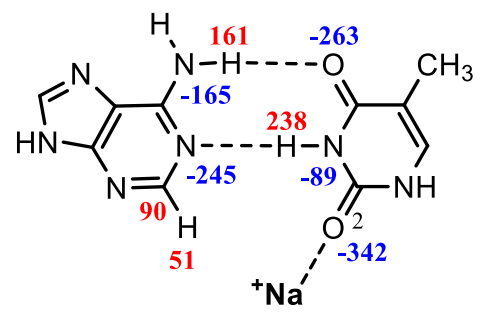

$-24.2$
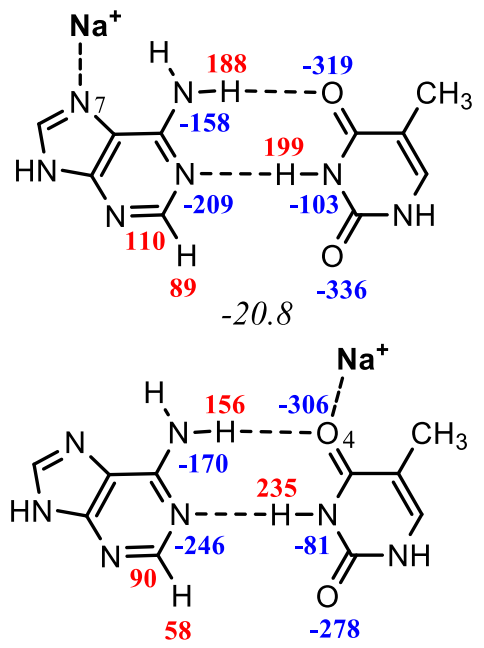

$-16.3$

Figure 6. VDD charges at the front atoms (in mili-electrons) of interacting adenine and thymine fragments in the geometry they adopt in AT pair and its metal complexes with $\mathrm{Na}^{+}$. Italic numbers denote interaction energy in $\mathrm{kcal} / \mathrm{mol}$ obtained in the gas-phase.
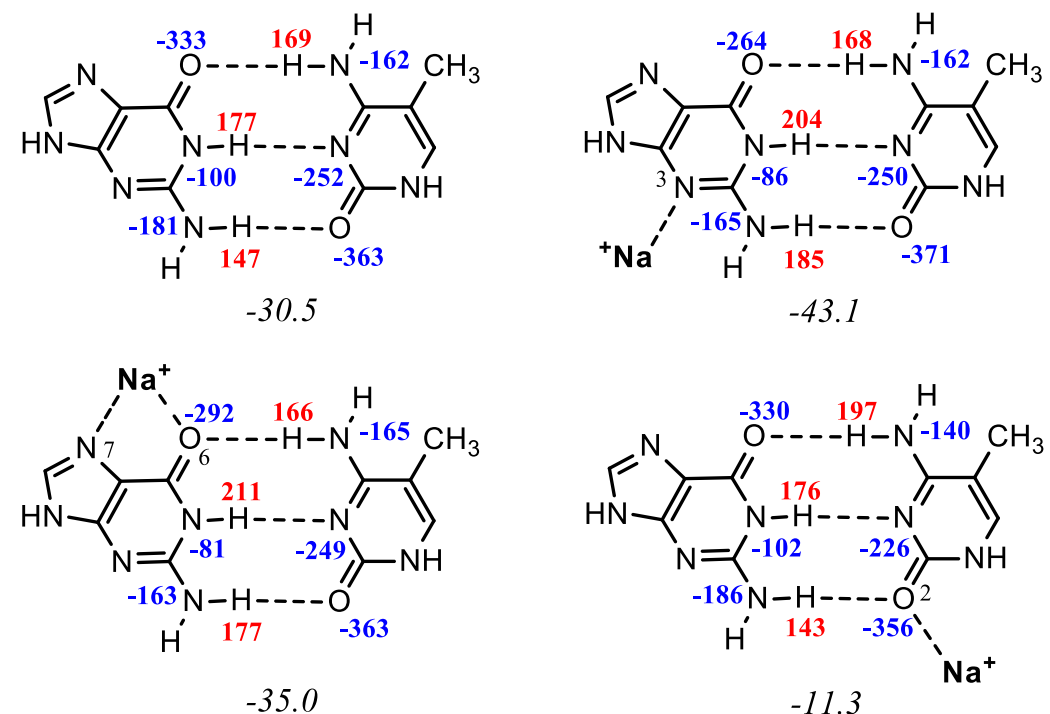

$-11.3$

Figure 7. VDD charges at the front atoms (in mili-electrons) of interacting guanine and cytosine fragments in the geometry they adopt in GC pair and its metal complexes with $\mathrm{Na}^{+}$. Italic numbers denote interaction energy in $\mathrm{kcal} / \mathrm{mol}$ obtained in the gas-phase. 
In aqueous solution, the effect of alkali metal cations on the individual $\mathrm{H}$-bonds in AT and GC pairs is very similar to that observed in the gas phase, but is less pronounced. All trends in the weakening or strengthening of H-bonds depending on the cation location are exactly the same as in the gas phase.

When considering the order of strength of individual H-bonds, we found that the solvent effect is more crucial for the GC pair. The order in aqueous solution $(\mathbf{b}>\mathbf{c}>\mathbf{a})$ is quite different than in the gas phase $(\mathbf{a}>\mathbf{b}>\mathbf{c})$, unlike to the AT pair where the H-bond $\mathbf{b}$ is the strongest in both environments (Table 5). The order determined by NBO approach generally coincides with the results from QTAIM analysis. The sequence can be inverted when two bonds are comparable in strength. In aqueous solution, the H-bond $\mathbf{b}$ is the strongest in both base pairs. The obtained results are in good agreement with the trends observed for individual $\mathrm{H}$-bonds in AT and GC pairs with cationic substituents at the $\mathrm{C} 8$ position of $\mathrm{A}$ and $\mathrm{G}$ or $\mathrm{C} 6$ position of $\mathrm{T}$ and C. ${ }^{[62,85,86,87]}$

Table 5. Ordering of individual H-bonds in Watson-Crick base pairs according to their strength.

\begin{tabular}{lll|ll}
\hline & \multicolumn{2}{l|}{ Order in gas phase } & \multicolumn{2}{l}{ Order in water } \\
& QTAIM & NBO & QTAIM & NBO \\
\hline AT & $\mathbf{b}>\mathbf{a}$ & $\mathbf{b}>\mathbf{a}$ & $\mathbf{b}>\mathbf{a}$ & $\mathbf{b}>\mathbf{a}$ \\
AT_MN3 & $\mathrm{b}>\mathrm{a}$ & $\mathrm{a}>\mathrm{b}$ & $\mathrm{b}>\mathrm{a}$ & $\mathrm{b}>\mathrm{a}$ \\
AT_MN7 & $\mathrm{a}>\mathrm{b}$ & $\mathrm{a}>\mathrm{b}$ & $\mathrm{b}>\mathrm{a}$ & $\mathrm{b}>\mathrm{a}$ \\
AT_MO2 & $\mathrm{b}>\mathrm{a}$ & $\mathrm{b}>\mathrm{a}$ & $\mathrm{b}>\mathrm{a}$ & $\mathrm{b}>\mathrm{a}$ \\
AT_MO4 & $\mathrm{b}>\mathrm{a}$ & $\mathrm{b}>\mathrm{a}$ & $\mathrm{b}>\mathrm{a}$ & $\mathrm{b}>\mathrm{a}$ \\
& & & & \\
GC & $\mathbf{a}>\mathbf{b}>\mathbf{c}$ & $\mathbf{a}>\mathbf{b}>\mathbf{c}$ & $\mathbf{b}>\mathbf{c}>\mathbf{a}$ & $\mathbf{b}>\mathbf{c}>\mathbf{a}$ \\
GC_MN3 & $\mathrm{c}>\mathrm{b}>\mathrm{a}$ & $\mathrm{c}>\mathrm{b}>\mathrm{a}$ & $\mathrm{b}>\mathrm{c}>\mathrm{a}$ & $\mathrm{b}>\mathrm{c}>\mathrm{a}$ \\
GC_MN7,O6 & $\mathrm{b}>\mathrm{c}>\mathrm{a}$ & $\mathrm{b}>\mathrm{c}>\mathrm{a}$ & $\mathrm{b}>\mathrm{c}>\mathrm{a}$ & $\mathrm{b}>\mathrm{c}>\mathrm{a}$ \\
GC_MO2 & $\mathrm{a}>\mathrm{b}>\mathrm{c}$ & $\mathrm{a}>\mathrm{b}>\mathrm{c}$ & $\mathrm{b}>\mathrm{a}>\mathrm{c}$ & $\mathrm{b}>\mathrm{a}>\mathrm{c}$ \\
\hline
\end{tabular}

\subsection{Effect of cations on aromaticity}

Aromaticity of nucleobases was estimated by geometry-based aromaticity index HOMA $_{\text {tot }}$ for the whole ring systems of purine and pyrimidine (global aromaticity), and by $\mathrm{HOMA}_{5}$ and $\mathrm{HOMA}_{6}$ indices for particular five- and six-membered rings of purine nucleobases (local aromaticity); the obtained values are shown in the Supporting Information (Tables S10 and S11) and summarized in Table 6. In all cases, the interactions with cations lead to increases of the HOMA index of pyrimidine bases in both AT and GC pairs, regardless to the coordination site and environment. In the gas phase, due to cation coordination the $\mathrm{HOMA}_{6}$ value increases maximally by 0.147 for thymine and 0.062 for cytosine, whereas in water this increase is smaller, namely by 0.081 and 0.021 for thymine and cytosine, respectively. It should also be noted that the change in the environment from the gas phase to the aqueous solution causes a significant increase in the aromaticity of the pyrimidine rings in AT and GC pairs without cation (by 0.123 and 0.087 HOMA units for thymine and cytosine, respectively), in 
agreement with the results reported by Cysewski and Szefler. ${ }^{88}$ Solvation stabilizes the resonance structures with charge separation (AT2 and GC2 in Scheme 2) and this explains the increase in the aromaticity of the pyrimidine bases. Such changes in the HOMA index of purine bases are much smaller. The $\pi$-electron delocalization in purine system may decrease or increase depending on the cation location. Considering $\mathrm{HOMA}_{\text {tot }}$, interactions of metal cations with nitrogen atoms of adenine or guanine cause the aromaticity decrease, while the interactions with oxygen atoms of thymine or cytosine promote an increase in the HOMA $\mathrm{Atot}_{\text {t }}$ index. If we consider local aromaticity of purine system, it can be observed that electronic structure of six-membered rings is more flexible to changes caused by interactions with metal cations than that of the five-membered ones. This can be explained by the presence of functional groups which interact with cations and cause the greatest geometric and aromaticity changes, increasing the weight of the resonance structures AT3 and GC3 (Scheme 2). ${ }^{26}$ The $\mathrm{HOMA}_{6}$ changes within the range of 0.069 HOMA units for adenine and 0.185 for guanine in the gas phase, while in water this range is only 0.007 and 0.071 . The six-membered ring of adenine is the most aromatic ring among all nucleobases and its $\pi$-electron system hardly changes due to the metal binding. Nevertheless, the aromatic character of the six-membered ring of both adenine and guanine is decisive for aromaticity of a whole purine system. ${ }^{89}$

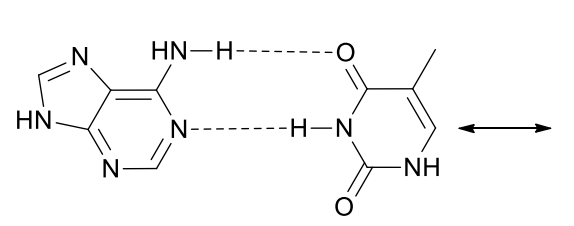

AT1

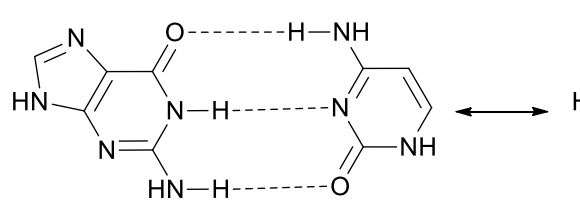

GC1

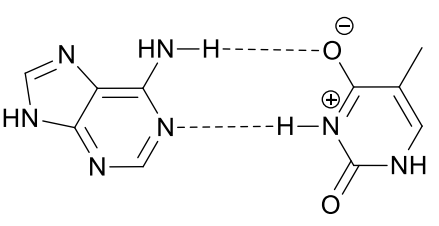

AT2

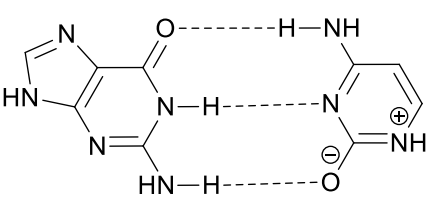

GC2

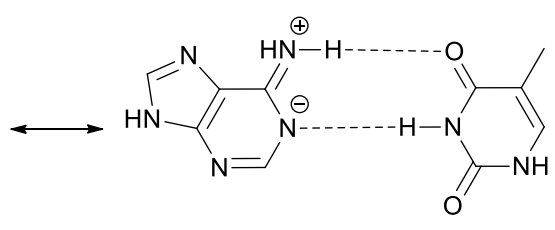

AT3

Scheme 2. Resonance forms of the AT and GC pairs.

In general, influence of metal cations on the global and local aromaticity of AT and GC pairs is significantly greater in the gas phase than in the aqueous solution. The observed smaller influence of cations on HOMA values when the gas phase change on the water environment most likely can be attributed to the increase in distance between cations $\mathrm{M}^{+}$and basic centers, resulting from the increased dissociating power of the environment (increase in $\varepsilon$ from 1 to 78 ). Greater aromaticity changes are observed when metal cation interacts with functional groups (amino and oxo). Metal coordination always leads to monotonic changes in aromaticity in line with the increase of metal cationic radius. Changes in aromaticity of the six- and fivemembered rings of nucleobase pairs caused by the metal cations can be further used to finetune $\pi-\pi$ and cation- $\pi$ interactions in their stacked complexes. 
Table 6. Global and local HOMA index values for AT and GC pairs and their complexes with metal cations (minimal and maximal values only) obtained in the gas phase and aqueous solution; the location of the cation is given in parenthesis.

\begin{tabular}{|c|c|c|c|c|}
\hline & $\mathrm{HOMA}_{5}$ & $\mathrm{HOMA}_{6}$ & HOMA $_{\text {tot }}$ & \multirow{2}{*}{$\begin{array}{l}\mathrm{HOMA}_{6} \\
\text { thymine }\end{array}$} \\
\hline & \multicolumn{3}{|c|}{$\begin{array}{c}\text { Gas phase } \\
\text { adenine }\end{array}$} & \\
\hline $\begin{array}{l}\text { AT } \\
\text { AT_M min. } \\
\text { AT_M max. } \\
\text { range }\end{array}$ & $\begin{array}{l}\mathbf{0 . 8 1 1} \\
0.796(\mathrm{~N} 7) \\
0.834(\mathrm{O} 2) \\
0.038\end{array}$ & $\begin{array}{l}\mathbf{0 . 9 3 6} \\
0.882(\mathrm{~N} 3) \\
0.951(\mathrm{O} 4) \\
0.069 \\
\quad \text { guanine }\end{array}$ & $\begin{array}{l}\mathbf{0 . 8 7 4} \\
0.844(\mathrm{~N} 3) \\
0.889(\mathrm{O} 4) \\
0.045\end{array}$ & $\begin{array}{l}\mathbf{0 . 5 0 0} \\
0.503(\mathrm{O} 2) \\
0.647(\mathrm{O} 4) \\
0.144 \\
\text { cytosine }\end{array}$ \\
\hline $\begin{array}{l}\text { GC } \\
\text { GC_M min. } \\
\text { GC_M max } \\
\text { range }\end{array}$ & $\begin{array}{l}\mathbf{0 . 7 9 1} \\
0.792(\mathrm{~N} 3) \\
0.822(\mathrm{~N} 7, \mathrm{O} 6) \\
0.030\end{array}$ & $\begin{array}{l}\mathbf{0 . 7 6 6} \\
0.697(\mathrm{~N} 3) \\
0.882(\mathrm{~N} 7, \mathrm{O} 6) \\
0.185 \\
\quad \begin{array}{c}\text { Aqueous so } \\
\text { adenine }\end{array}\end{array}$ & $\begin{array}{l}\mathbf{0 . 7 6 5} \\
0.719(\mathrm{~N} 3) \\
0.841(\mathrm{~N} 7, \mathrm{O} 6) \\
0.122\end{array}$ & $\begin{array}{l}\mathbf{0 . 6 8 4} \\
0.719(\mathrm{O} 2) \\
0.746(\mathrm{~N} 7, \mathrm{O} 6) \\
0.027 \\
\text { thymine }\end{array}$ \\
\hline $\begin{array}{l}\text { AT } \\
\text { AT_M min. } \\
\text { AT_M max. } \\
\text { range }\end{array}$ & $\begin{array}{l}\mathbf{0 . 8 3 7} \\
0.837(\mathrm{O} 2 / \mathrm{O} 4) \\
0.846(\mathrm{~N} 7) \\
0.009\end{array}$ & $\begin{array}{l}\mathbf{0 . 9 2 8} \\
0.926(\mathrm{~N} 3) \\
0.933(\mathrm{~N} 7) \\
0.007 \\
\quad \text { guanine }\end{array}$ & $\begin{array}{l}\mathbf{0 . 8 8 4} \\
0.883(\mathrm{~N} 3) \\
0.890(\mathrm{~N} 7) \\
0.007\end{array}$ & $\begin{array}{l}\mathbf{0 . 6 2 3} \\
0.629(\mathrm{~N} 3 / \mathrm{N} 7) \\
0.704(\mathrm{O} 4) \\
0.075 \\
\text { cytosine }\end{array}$ \\
\hline $\begin{array}{l}\text { GC } \\
\text { GC_M min. } \\
\text { GC_M max } \\
\text { range }\end{array}$ & $\begin{array}{l}\mathbf{0 . 8 2 3} \\
0.823(\mathrm{O} 2) \\
0.845(\mathrm{~N} 7, \mathrm{O} 6) \\
0.022\end{array}$ & $\begin{array}{l}\mathbf{0 . 8 1 0} \\
0.809(\mathrm{O} 2 / \mathrm{N} 3) \\
0.880(\mathrm{~N} 7, \mathrm{O} 6) \\
0.071\end{array}$ & $\begin{array}{l}\mathbf{0 . 8 0 6} \\
0.806(\mathrm{O} 2 / \mathrm{N} 3) \\
0.835(\mathrm{~N} 7, \mathrm{O} 6) \\
0.029\end{array}$ & $\begin{array}{l}\mathbf{0 . 7 7 1} \\
0.772(\mathrm{~N} 3) \\
0.792(\mathrm{O} 2) \\
0.020\end{array}$ \\
\hline
\end{tabular}

\section{Conclusions}

In this work, we have investigated the effect of alkali metal cations on the hydrogen bonding in DNA base pairs. In the gas phase, the metal cations substantially affect the strength of H-bonds making them stronger or weaker depending on the coordination position. The nature of bonding between two nucleobases does not change much upon metal coordination: the largest contribution is the electrostatic interactions followed by the orbital interactions and dispersion forces. When metal cations interact with oxygen atoms of thymine/cytosine, the orbital interactions term is slightly larger than in the complexes with metal coordination at the nitrogen atoms of adenine/guanine due to involvement of the metal in the orbital interactions. The metal cation stabilizes the accepting $\sigma$-LUMOs of thymine/cytosine and reduces the orbital-energy gap with lone-pair donor orbitals of the adenine/guanine.

Considering three descriptors of individual H-bonds: H-bond length, bond energy from NBO analysis, and delocalization index from QTAIM calculations, we found that in AT pair 
the strongest bond is the bond $\mathbf{b}$, while in GC pair it is the bond $\mathbf{a}$. Interactions of metal cations with the nitrogen atoms of adenine/guanine promotes the weakening of the strongest bonds, but interactions with the oxygen atoms of thymine/cytosine contribute to their further strengthening.

The coordination energy between cation and base pair depends both on the location of cation and on its type. The strength of interactions always decreases with increase in ionic radii, i.e. from $\mathrm{Li}^{+}$to $\mathrm{K}^{+}$. Interactions with the oxygen atoms are regularly stronger than with the nitrogen ones. All energetic terms excluding Pauli repulsion change monotonically with increasing of a distance between cation and nucleobase. The Pauli repulsion is smaller for the interaction with $\mathrm{Na}^{+}$than with $\mathrm{Li}^{+}$and $\mathrm{K}^{+}$, because of a balance in interatomic distance and ionic radius of the cation.

According to HOMA index, the aromaticity of thymine and cytosine rings increases upon coordination of metal cations regardless to the site of interaction. The six-membered ring of adenine is the most aromatic ring among all nucleobases and its aromaticity hardly changes due to the metal binding.

In solution ( $\varepsilon=78.4$ ), the effects of alkali metal cations on individual and total H-bonds, as well as on aromaticity of rings are very similar to those observed in the gas phase, but are less pronounced.

\section{Acknowledgements}

M. Solà and O.A.S. are grateful to the Ministerio de Economía y Competitividad (MINECO) of Spain (project CTQ2017-85341-P and Juan de la Cierva formación contract FJCI-201732757 to O.A.S.) and the Generalitat de Catalunya (project 2017SGR39). HS and TMK thank the National Science Centre of Poland for supporting this work under the grant no. UMO2016/23/B/ST4/00082. M. Swart acknowledges MICINN/MINECO (projects CTQ2014 59212 P, CTQ2015-70851-ERC, CTQ2017-87392-P), GenCat (2014SGR1202, 2017SGR1434 and XRQTC network) and European Fund for Regional Development (FEDER, UNGI104E801). C.F.G. thanks the Netherlands Organization for Scientific Research (NWO) for financial support.

\section{References}

[1] V. Tereshko, G. Minasov, M. Egli, J. Am. Chem. Soc. 1999, 121, 3590-3595.

[2] V. P Denisov, B. Halle, Proc. Natl. Acad. Sci. USA 2000, 97, 629-633.

[3] P. Varnai, K. Zakrzewska, Nucleic Acids Res. 2004, 32, 4269-4280. 
[4] R. Sÿtefl, J. Koca, J. Am. Chem. Soc. 2000, 122, 5025-5033.

[5] Y. Timsit, S. Bombard, RNA 2007, 13, 2098-2107.

[6] S. B. Howerton, A. Nagpal, L. D. Williams, Biopolymers 2003, 69, 87-99.

[7] V. Tereshko, C. J. Wilds, G. Minasov, T. P. Prakash, M. A. Maier, A. Howard, Z. Wawrzak, M. Manoharan, M. Egli, Nucleic Acids Res. 2001, 29, 1208-1215.

[8] S. B. Howerton, C. C. Sines, D. VanDerveer, L. D. Williams, Biochemistry 2001, 40, 10023-10031.

[9] M. Egli, Chem. Biol. 2002, 9, 277-286.

[10] N.V. Hud, M. Polak, Curr. Opin. Struct. Biol. 2001, 11, 293-301.

[11] M. A. Young, B. Jayaram, D. L. Beveridge, J. Am. Chem. Soc. 1997, 119, 59-69.

[12] P. D. Dans, I. Faustino, F. Battistini, K. Zakrzewska, R. Lavery, M. Orozco, Nucleic Acids Res. 2014, 42, 11304-11320.

[13] R. K. O. Sigel, H. Sigel, Acc. Chem. Res. 2010, 43, 974-984.

[14] S. Verma, A. K. Mishra, J. Kumar, Acc. Chem. Res. 2010, 43, 79-91.

[15] M. T. Rodgers, P. B. Armentrout, J. Am. Chem. Soc. 2000, 122, 8548-8558.

[16] J. Chen, H. Ai, Y. Zhao, J. Liu, J. Phys. Org. Chem. 2012, 25, 126-131.

[17] J.A. Subirana, M. Soler-Lopez, Annu. Rev. Biophys. Biomol. Struct. 2003, 32, 27-45.

[18] N. Russo, M. Toscano, A. Grand, J. Am. Chem. Soc. 2001, 123, 10272-10279.

[19] M. Kabeláč, P. Hobza, J. Phys. Chem. B 2006, 110, 14515-14523.

[20] H. M. Berman, W. K. Olson, D. L. Beveridge, J. Westbrook, A. Gelbin, T. Demeny, S.H. Hsieh, A. R. Srinivasan, B. Schneider, Biophys. J. 1992, 63, 751-759.

[21] R. Oliva, L. Cavallo, J. Phys. Chem. B 2009, 113, 15670-15678.

[22] J.V. Burda, J. Sponer, J. Leszczynski, P. Hobza, J. Phys. Chem. B 1997, 101, 9670-9677.

[23] J. Sponer, J.V. Burda, M. Sabat, J. Leszczynski, P. Hobza, J. Phys. Chem. A 1998, 102, 5951-5957.

[24] J. Sponer, M. Sabat, J.V. Burda, J. Leszczynski, P. Hobza, J. Phys. Chem. B 1999, 103, 2528-2534.

[25] T. Biver, Coord. Chem. Rev. 2013, 257, 2765- 2783.

[26] J. Poater, M. Sodupe, J. Bertran, M. Solà, Mol. Phys. 2005, 103, 163-173.

[27] Y. Zhang, K. Huang, J. Mol. Struct.: THEOCHEM 2007, 822, 57-64.

[28] A. Robertazzi, J. A. Platts, J. Biol. Inorg. Chem. 2005, 10, 854-866.

[29] F. Zaccaria, G. Paragi, C. Fonseca Guerra, Phys. Chem. Chem. Phys. 2016, 18, 2089520904.

[30] F. Zaccaria, C. Fonseca Guerra, Chem. Eur. J. 2018, 24, 16315 - 16322. 
[31] G. te Velde, F. M. Bickelhaupt, S. J. A. van Gisbergen, C. Fonseca Guerra, E. J. Baerends, J. G. Snijders, T. Ziegler, J. Comput. Chem. 2001, 22, 931.

[32] F. M. Bickelhaupt, E. J. Baerends, Rev. Comput. Chem. 2000, 15, 1.

[33] ADF 2012, SCM, Theoretical Chemistry, Vrije Universiteit, Amsterdam (The Netherlands), http://www.scm.com

[34] M. Swart, F.M. Bickelhaupt, J. Comput. Chem. 2008, 29, 724-734.

[35] A. D. Becke, Phys. Rev. A 1988, 38, 3098-3100.

[36] C. Lee, W. Yang, R. G. Parr, Phys. Rev. B 1988, 37, 785-789.

[37] S. Grimme, J. Antony, S. Ehrlich, H. Krieg, J. Chem. Phys. 2010, 132, 154104.

[38] A. D. Becke, E. R. Johnson, J. Chem. Phys. 2005, 122, 154104.

[39] C. Fonseca Guerra, T. van der Wijst, J. Poater, M. Swart, F. M. Bickelhaupt, Theor. Chem. Acc. 2010, 125, 245-252.

[40] O.A. Stasyuk, D. Jakubec, J. Vondrášek, P. Hobza, J. Chem. Theory Comput. 2017, 13, $877-885$.

[41] J. G. Snijders, E. J. Baerends, P. Vernooijs, At. Data Nucl. Data Tables 1981, 26, 483.

[42] A. Klamt, G. Schüürmann, J. Chem. Soc., Perkin Trans. 2 1993, 799-805.

[43] A. Klamt, J. Phys. Chem. 1995, 99, 2224-2235.

[44] C.C. Pye, T. Ziegler, Theor. Chem. Acc. 1999, 101, 396-408.

[45] A. Cuervo, P. D. Dans, J. L. Carrascosa, M. Orozco, L. Fumagalli, Proc. Natl. Acad. Sci. U. S. A. 2014, 111, 3624-3630.

[46] T. A. Hamlin, J. Poater, C. Fonseca Guerra, F. M.Bickelhaupt, Phys. Chem. Chem. Phys. 2017, 19, 16969-16978.

[47] T. van der Wijst, B. Lippert, C. Fonseca Guerra, M. Swart, F. M. Bickelhaupt, J. Biol. Inorg. Chem. 2010, 15, 387-397.

[48] C.-S. Zuo, O. Wiest, Y.-D. Wu, J. Phys. Chem. A 2009, 113, 12028-12034.

[49] C. M. Choi, J. Heo, N. J. Kim, Chem. Cent. J. 2012, 6, 84-91.

[50] T. van der Wijst, C. Fonseca Guerra, M. Swart, F. M. Bickelhaupt, Chem. Phys. Lett. 2006, $426,415-421$.

[51] T. Ziegler, A. Rauk, Theor. Chim. Acta 1977, 46, 1-10.

[52] T. Ziegler, A. Rauk, Inorg. Chem. 1979, 18, 1755-1759

[53] T. Ziegler, A. Rauk, Inorg. Chem. 1979, 18, 1558-1565.

[54] S. Grimme, J. Comput. Chem. 2004, 25, 1463-1473.

[55] S. Grimme, J. Comput. Chem. 2006, 27, 1787-1799. 
[56] F.M. Bickelhaupt, N. J. R. van Eikema Hommes, C. Fonseca Guerra, E.J. Baerends, Organometallics 1996, 15, 2923-2931.

[57] C. Fonseca Guerra, J.-W. Handgraaf, E. J. Baerends, F. M. Bickelhaupt, J. Comput. Chem. 2004, 25, 189-210.

[58] G. te Velde, E. J. Baerends, J. Comp. Phys. 1992, 99, 84-98.

[59] F. Weinhold, C. R. Landis, Valency and Bonding. A Natural Bond Orbital Donor-Acceptor Perspective, Cambridge University Press, Cambridge, U.K., 2005

[60] R.F.W. Bader, Atoms in Molecules: A Quantum Theory, Oxford University Press, New York, 1990

[61] E.D. Glendening, J.K. Badenhoop, A.E. Reed, J.E. Carpenter, J.A. Bohmann, C.M. Morales, F. Weinhold, NBO 5.G, Theoretical Chemistry Institute, University of Wisconsin (Madison, WI), 2004

[62] H. Szatylowicz, N. Sadlej-Sosnowska, J. Chem. Inf. Model. 2010, 50, 2151-2161.

[63] T. A. Keith, AIMAll (Version 12.06.03), TK Gristmill Software, Overland Park KS (USA), 2013

[64] J.Poater, X. Fradera, M. Solà, M. Duran, S. Simon, Chem. Phys. Lett. 2003, 369, 248-255.

[65] D. Hugas, L. Guillaumes, M. Duran, S. Simon, Comput. Theor. Chem. 2012, 998, 113119.

[66] J. Poater, M. Solà, M. Duran, X. Fradera, Theor. Chem. Acc. 2002, 107, 362-371.

[67] J. Kruszewski, T. M. Krygowski, Tetrahedron Lett. 1972, 3839-3842.

[68] T. M. Krygowski. J. Chem. Inf. Comput. Sci. 1993, 33, 70-78.

[69] L. Guillaumes, S. Simon, C. Fonseca Guerra, ChemistryOpen 2015, 4, 318 - 327.

[70] C. Fonseca Guerra, F. M. Bickelhaupt, J. G. Snijders, E. J. Baerends, Chem. Eur. J. 1999, $5,3581-3594$.

[71] Y. Wu, R. Sa, Q. Li, Y. Wei, K. Wu, Chem. Phys. Lett. 2009, 467, 387-392.

[72] S. C. C. van der Lubbe, C. Fonseca Guerra, Chem. Asian J. 2019, 14, 2760.

[73] J. Muñoz, J. Sponer, P. Hobza, M. Orozco, F. Javier Luque, J. Phys. Chem. B 2001, 105, 6051-6060.

[74] O. A. Stasyuk, H. Szatylowicz, T. M. Krygowski, Org. Biomol. Chem. 2014, 12, 456-466.

[75] O.A. Stasyuk, H. Szatylowicz, T.M. Krygowski, Croat. Chem. Acta 2014, 87, 335-342.

[76] O.A. Stasyuk, H. Szatylowicz, T.M. Krygowski, Org. Biomol. Chem. 2014, 6476-6483.

[77] O.A. Stasyuk, H. Szatylowicz, T.M. Krygowski, Struct. Chem. 2016, 27, 111-118.

[78] A. Asensio, N. Kobko, J. J. Dannenberg, J. Phys.Chem. A 2003, 107, 6441-6443.

[79] M. Mitoraj, A. Michalak, T. Ziegler, J. Chem. Theory Comput. 2009, 5, 962-975. 
[80] H. Szatylowicz, A. Jezierska, N. Sadlej-Sosnowska, Struct. Chem. 2016, 27, 367-376.

[81] A. Halder, D. Data, P. P. Seelam, D. Bhattacharyya, A. Mitra, ACS Omega 2019, 4, 73547368.

[82] H. Dong, W. Hua, S. Li, J. Phys. Chem. A 2007, 111, 2941-2945.

[83] A. Ebrahimi, S.M.H. Khorassani, H. Delarami, Chem. Phys. 2009, 365, 18-23.

[84] A. Ebrahimi, S. M. H. Khorassani, H. Delarami, H. Esmaeeli, J. Comput. Aided Mol. Des. 2010, 24, 409-416.

[85] C. Fonseca Guerra, T. van der Wijst, F. M. Bickelhaupt, Chem. Eur. J. 2006, 12, 3032 3042 .

[86] C. Fonseca Guerra, T. van der Wijst, F. M. Bickelhaupt, ChemPhysChem 2006, 7, 1971 1979.

[87] H. Szatylowicz, O.A. Stasyuk, T.M. Krygowski, Substituent Effects in Heterocyclic Systems, Chapter 4 in Advances in Heterocyclic Chemistry 2015, 116, 137-192.

[88] P. Cysewski, B. Szefler, J. Mol. Model. 2010, 16, 1709-1720.

[89] H. Szatylowicz, O.A. Stasyuk, T.M. Krygowski, Calculating the Aromaticity of Heterocycles, Chapter 9 in Advances in Heterocyclic Chemistry 2016, 120, 301-327. 